\title{
COMPONENT AND SYSTEM LEVEL RESEARCH OF VARIABLE CAPACITY HEAT PUMPS
}

\section{August 2013}

\section{Prepared by}

Jeffrey Munk, Oak Ridge National Laboratory

Christopher Halford, Ph.D., Oak Ridge National Laboratory

Roderick Jackson, Ph.D., Oak Ridge National Laboratory 


\section{DOCUMENT AVAILABILITY}

Reports produced after January 1, 1996, are generally available free via the U.S. Department of Energy (DOE) Information Bridge.

Web site http://www.osti.gov/bridge

Reports produced before January 1, 1996, may be purchased by members of the public from the following source.

National Technical Information Service

5285 Port Royal Road

Springfield, VA 22161

Telephone 703-605-6000 (1-800-553-6847)

TDD 703-487-4639

Fax 703-605-6900

E-mail info@ntis.gov

Web site http://www.ntis.gov/support/ordernowabout.htm

Reports are available to DOE employees, DOE contractors, Energy Technology Data Exchange (ETDE) representatives, and International Nuclear Information System (INIS) representatives from the following source.

Office of Scientific and Technical Information

P.O. Box 62

Oak Ridge, TN 37831

Telephone 865-576-8401

Fax 865-576-5728

E-mail reports@osti.gov

Web site http://www.osti.gov/contact.html

This report was prepared as an account of work sponsored by an agency of the United States Government. Neither the United States Government nor any agency thereof, nor any of their employees, makes any warranty, express or implied, or assumes any legal liability or responsibility for the accuracy, completeness, or usefulness of any information, apparatus, product, or process disclosed, or represents that its use would not infringe privately owned rights. Reference herein to any specific commercial product, process, or service by trade name, trademark, manufacturer, or otherwise, does not necessarily constitute or imply its endorsement, recommendation, or favoring by the United States Government or any agency thereof. The views and opinions of authors expressed herein do not necessarily state or reflect those of the United States Government or any agency thereof. 
ORNL/TM-2013/36

Energy and Transportation Science Division

\section{Component and System Level Research of Variable Capacity Heat Pumps}

August 2013

Jeffrey Munk, Oak Ridge National Laboratory Christopher Halford, Ph.D., Oak Ridge National Laboratory Roderick Jackson, Ph.D., Oak Ridge National Laboratory

Prepared by

OAK RIDGE NATIONAL LABORATORY

Oak Ridge, Tennessee 37831-6283

managed by

UT-BATTELLE, LLC

for the

U.S. DEPARTMENT OF ENERGY

under contract DE-AC05-00OR22725 


\section{ACKNOWLEDGEMENTS}

This work was funded and supported by the United States Department of Energy (DOE) and the Tennessee Valley Authority (TVA). A special thanks goes to TVA program manager David Dinse for providing these unique research homes as a testing platform. We would also like to thank Anthony Gehl for all of his work with the instrumentation and data collection and Van Baxter and Christopher Gray for serving as peer reviewers and helping to improve the quality of this report. 


\section{CONTENTS}

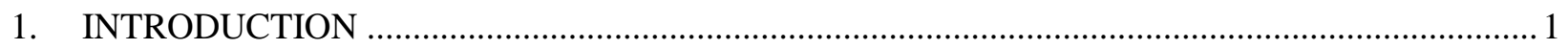

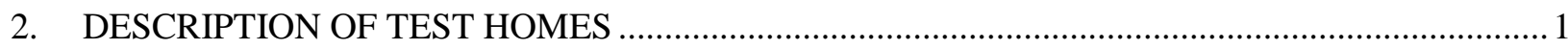

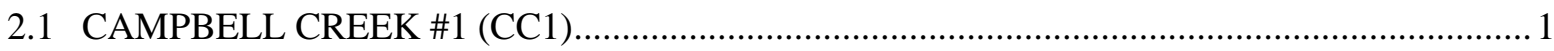

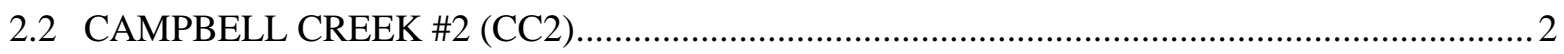

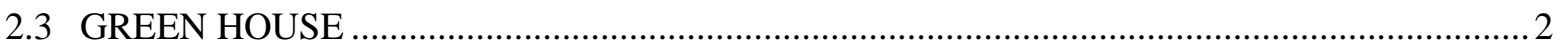

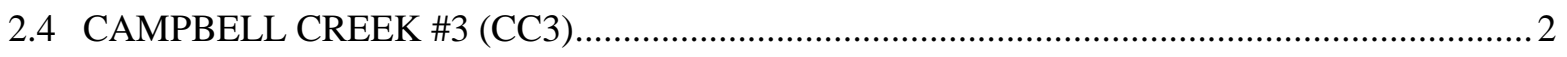

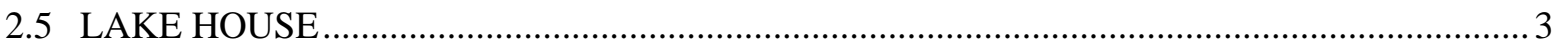

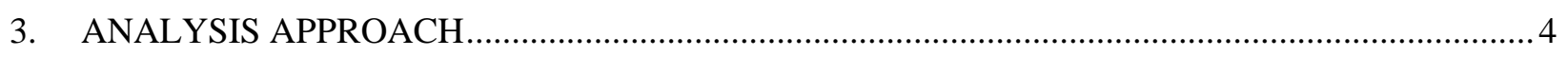

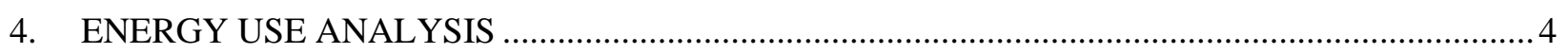

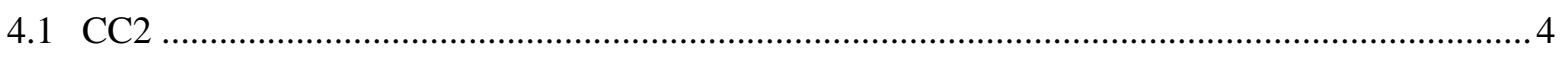

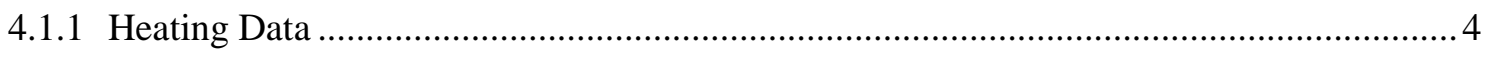

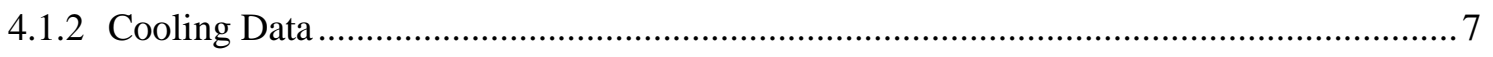

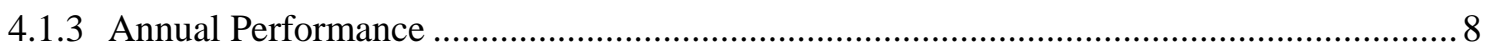

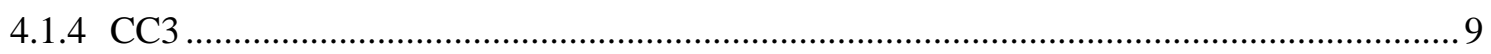

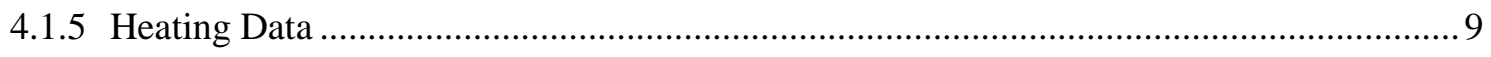

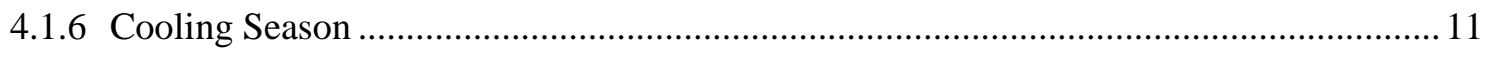

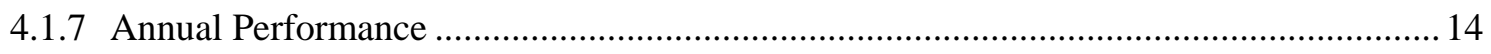

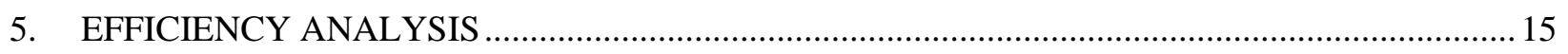

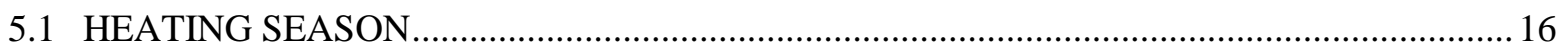

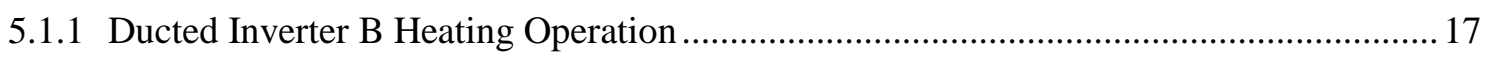

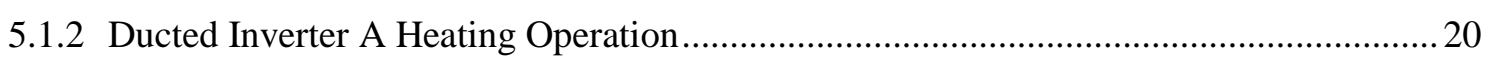

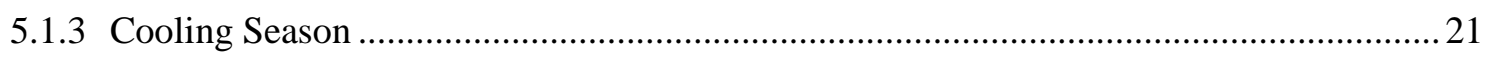

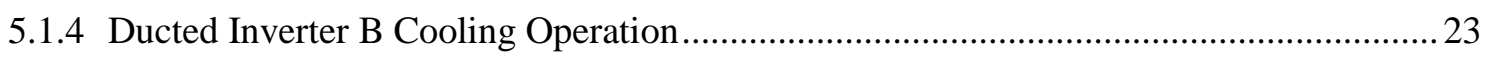

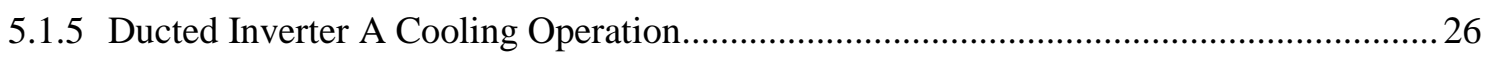

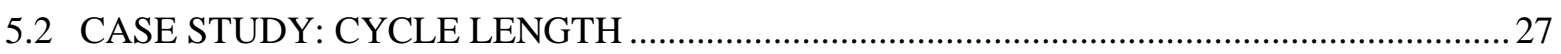

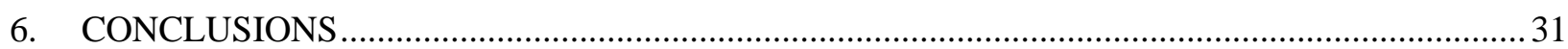

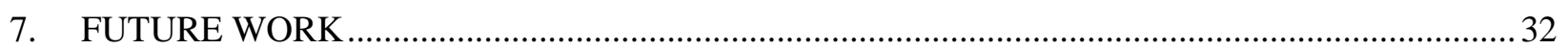

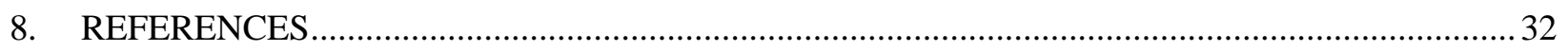

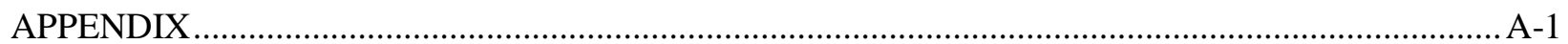




\section{LIST OF FIGURES}

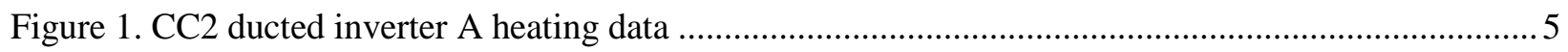

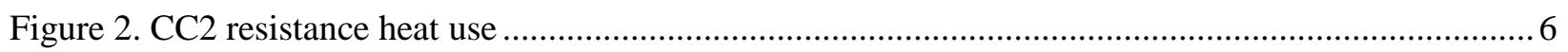

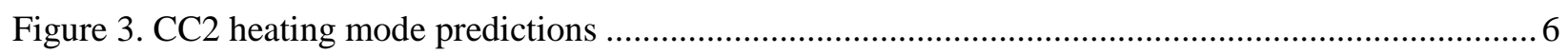

Figure 4. CC2 ducted inverter A cooling season data...................................................................... 7

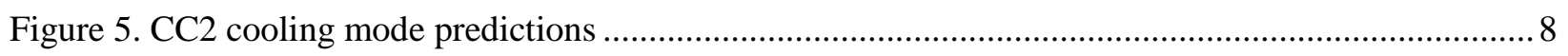

Figure 6. CC2 predicted TMY energy use for Knoxville, Tennessee ...................................................... 9

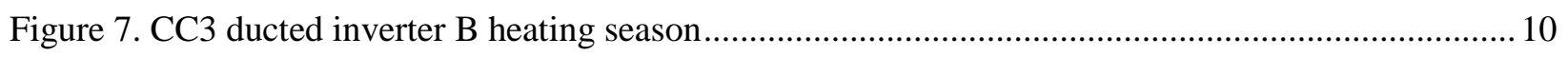

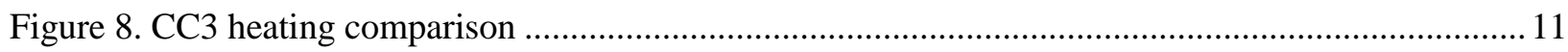

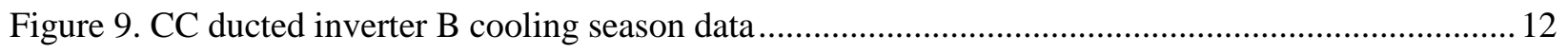

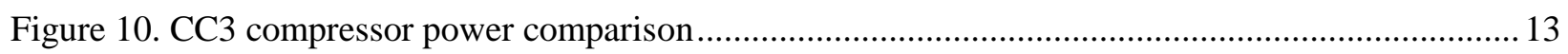

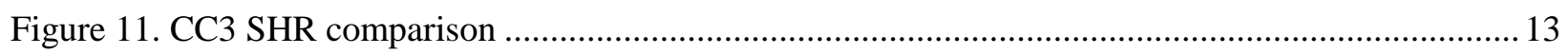

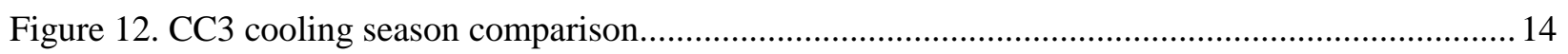

Figure 13. CC3 predicted TMY energy use for Knoxville, Tennessee................................................... 15

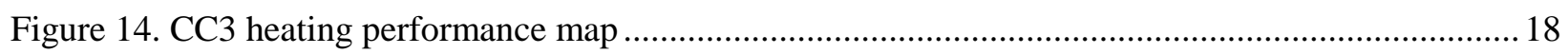

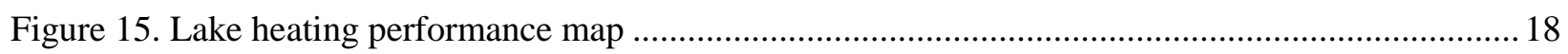

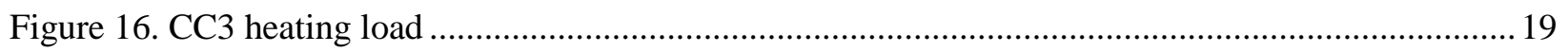

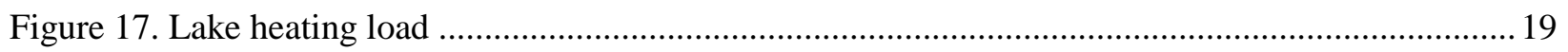

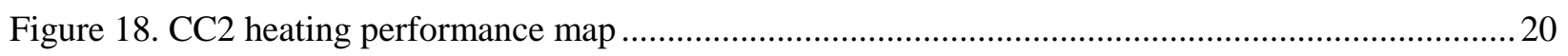

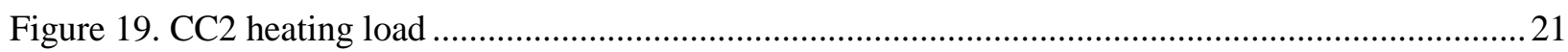

Figure 20. CC3 pre-damper adjustment performance map .............................................................2 23

Figure 21. CC3 post-damper adjustment performance map ........................................................... 23

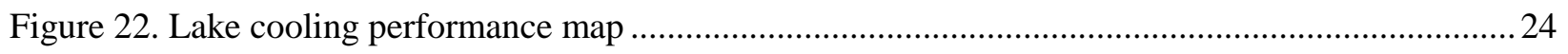

Figure 23. CC3 cooling load pre- and post-damper adjustment .........................................................2 25

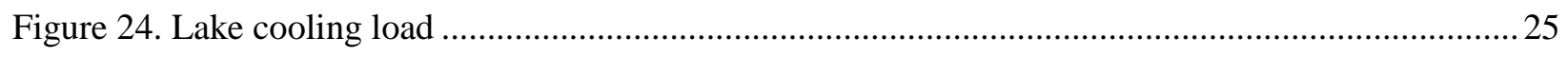

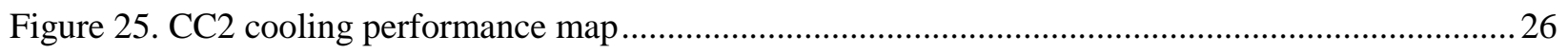

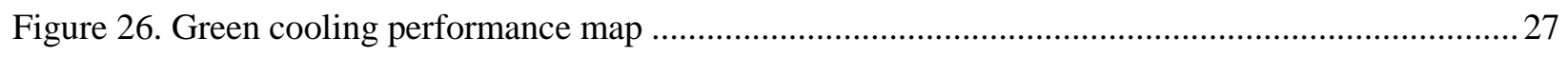

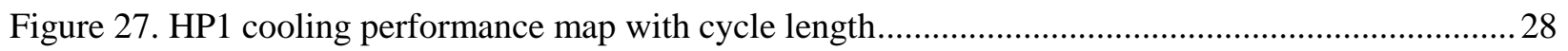

Figure 28. HP2 cooling performance color map with cycle length ......................................................29

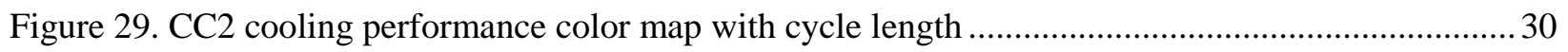




\section{LIST OF TABLES}

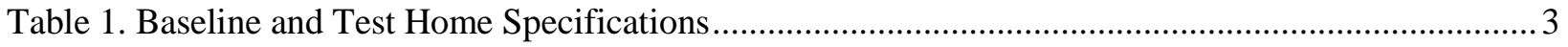

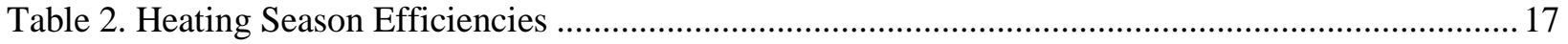

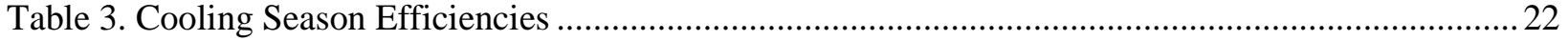





\section{INTRODUCTION}

With high cooling and heating efficiencies, variable capacity heat pumps are an emerging technology with the potential to substantially reduce the energy required for the heating and cooling of residential structures. In order for them to make an impact in this area, they must first be more widely accepted by the American consumer as an alternative to less expensive single speed systems. This acceptance, in large part, is based upon a greater understanding of how these systems perform in real world tests. To this end, this study will evaluate the energy consumption and efficiencies of four variable capacity heat pumps installed in two unoccupied research homes in Farragut, a suburb of Knoxville, Tennessee, one occupied home in downtown Knoxville, and one occupied home in Duluth, Georgia.

\section{DESCRIPTION OF TEST HOMES}

The study described in this report is based on measurements taken from four test homes that have been retrofitted with ducted heat pumps that have inverter driven compressors from one of two manufacturers (Mfrs.). Each of the homes is extensively instrumented with data acquisition systems to monitor energy consumption and HVAC performance. Two of the homes are unoccupied (CC2 and CC3), but have lighting, showers, appliances, and sensible and latent buildings loads controlled to simulate the human impact on energy use. These homes are located in the Campbell Creek subdivision of Farragut, Tennessee. Data is also available on the HVAC systems that were installed prior to the inverter heat pumps and will be used for comparison. The other two homes are occupied buildings that were retrofitted and instrumented as part of the "Building America" program. The first of these homes is located in downtown Knoxville, Tennessee, with the second in Duluth, Georgia. The following section gives a brief description of the construction and HVAC components for each of the four houses. For reference, a fifth

home, $\mathrm{CC} 1$, will also be described. This home has two single-stage heat pumps and provides a reference for a more conventional space conditioning system. The temperatures inside the unoccupied test homes were maintained as close as possible to the desired $71^{\circ} \mathrm{F}$ heating set point and $76^{\circ} \mathrm{F}$ cooling set point as measured via thermistors located near the thermostats. The homeowners in the occupied research homes were free to change their thermostat set point as they desired.

\subsection{CAMPBELL CREEK \#1 (CC1)}

This home was one of three research residential structures constructed in Farragut, Tennessee. CC1 uses standard construction methods typical for the region and has been used for baseline comparisons of whole house energy consumption. Although the home is unoccupied, occupancy is simulated by cycling plug loads, lighting, and appliances on and off at regularly scheduled times. Additionally, latent and sensible loads which would be created by actual occupants are also simulated as described in Christian et al. (2010).

The HVAC system consists of two, single-stage, air-source heat pumps, one for each of the two zones (upstairs and downstairs). Both systems have permanent split capacitor (PSC) indoor blower motors. 


\subsection{CAMPBELL CREEK \#2 (CC2)}

This home is the second of three research residential structures constructed in the Campbell Creek subdivision in Farragut, Tennessee. The structure utilizes slab construction with expanded polystyrene perimeter insulation, high performance windows, and a sealed attic and was designed to be representative of energy saving improvements which are available to homeowners as retrofit options to the $\mathrm{CC} 1$ baseline home. Like CC1, occupancy is simulated as described in Christian et al. (2010).

The HVAC system consists of an inverter driven compressor outdoor unit coupled to a ducted air handler (referred to as a "ducted inverter system" in this paper) installed in the sealed attic of the home. The indoor unit utilizes a variable speed blower with a brushless permanent magnet (BPM) motor as well as auxiliary electric resistance heat, and the living space is divided into two control zones (upstairs and downstairs).

The prior HVAC system was a single-stage, air-source heat pump with a BPM indoor blower motor that also had a zoning system that divided the home into upstairs and downstairs zones.

\subsection{GREEN HOUSE}

The Green House is an older (over 100 years) home located in Knoxville, Tennessee, which was retrofitted as part of the "Building America" program. Given the age of the building, the retrofit was quite extensive and included adding insulation to the walls, attic, and basement as well as installation of new windows and lighting as described in Boudreaux et al. (2012). Unlike the Campbell Creek homes, this house is occupied; so, there is no regimented control scheme for the appliances or HVAC components.

As part of the retrofit, the HVAC equipment was upgraded to the same variable speed system that is used in the $\mathrm{CC} 2$ house.

\subsection{CAMPBELL CREEK \#3 (CC3)}

Like $\mathrm{CC} 1$ and $\mathrm{CC} 2, \mathrm{CC} 3$ is an unoccupied research home in the Campbell Creek subdivision in Farragut, Tennessee. $\mathrm{CC} 1$ and $\mathrm{CC} 2$ share similar floor plans and square footage, but CC3 was designed to showcase energy saving construction techniques such as 2" X 6" framing, insulated slab, and R50 fiberglass ceiling insulation. As with the other Campbell Creek homes, occupancy is simulated as described in Christian et al. (2010).

The HVAC equipment for CC3 consists of an inverter driven compressor outdoor unit coupled to a ducted air handler with a BPM blower motor.

The system installed prior to the ducted inverter system was a two-stage, air-source heat pump (HP) that utilized a zoning system that divided the home into upstairs and downstairs zones. It also had a BPM indoor blower motor. 


\subsection{LAKE HOUSE}

The Lake House is a two-story home of 1700 square feet, located in Duluth, Georgia, which was built in 1985 and retrofitted under the same program as the Green House. Upgrades to the home include improved ductwork as well as the sealing and insulating of the attic space as described in Jackson et al. (2012). This is an occupied building like the Green House, and it uses the same HVAC components as CC3.

The specifications for the five houses are summarized in Table 1.

Table 1. Baseline and Test Home Specifications

\begin{tabular}{|c|c|c|c|}
\hline House & Location & $\begin{array}{c}\text { Size/ } \\
\text { Configuration }\end{array}$ & HVAC \\
\hline $\mathrm{CC} 1$ & Farragut, TN & $\begin{array}{l}2400 \mathrm{ft}^{2} \\
\text { Two Story }\end{array}$ & $\begin{array}{l}\text { Downstairs (HP1) Single-Stage } \\
\text { HP Heating Cap=16800 BTU/hr, HSPF=7.7 } \\
\text { Cooling Cap= } 17600 \mathrm{BTU} / \mathrm{hr}, \text { SEER=13.0 } \\
\text { Upstairs (HP2) Single-Stage HP } \\
\text { Heating Cap=25000 BTU/hr, HSPF=7.7 } \\
\text { Cooling Cap= } 30000 \mathrm{BTU} / \mathrm{hr}, \text { SEER }=13.0\end{array}$ \\
\hline $\mathrm{CC} 2$ & Farragut, TN & $\begin{array}{l}2400 \mathrm{ft}^{2} \\
\text { Two Story }\end{array}$ & $\begin{array}{l}\text { Ducted Inverter Mfr. A } \\
\text { Heating Cap=33400 BTU/hr, HSPF }=13.0 \\
\text { Cooling Cap }=35000 \text { BTU/hr, SEER }=20.5 \\
\text { Original Single-Stage HP } \\
\text { Heating Cap=34400 BTU/hr, HSPF=9.75 } \\
\text { Cooling Cap }=34600 \text { BTU/hr, SEER }=16.00\end{array}$ \\
\hline $\mathrm{CC} 3$ & Farragut, TN & $\begin{array}{l}2500 \mathrm{ft}^{2} \\
\text { Two Story }\end{array}$ & $\begin{array}{l}\text { Ducted Inverter Mfr. B } \\
\text { Heating Cap=27000 BTU/hr, HSPF }=8.9 \\
\text { Cooling Cap }=24000 \mathrm{BTU} / \mathrm{hr}, \mathrm{SEER}=18.0 \\
\text { Original Two-Stage HP } \\
\text { Heating Cap=23000 BTU/hr, HSPF }=9.50 \\
\text { Cooling Cap }=24000 \mathrm{BTU} / \mathrm{hr}, \mathrm{SEER}=16.0\end{array}$ \\
\hline Lake & Duluth, GA & $\begin{array}{l}1700 \mathrm{ft}^{2} \\
\text { Two Story }\end{array}$ & $\begin{array}{l}\text { Ducted Inverter Mfr. B } \\
\text { Heating Cap }=27000 \mathrm{BTU} / \mathrm{hr}, \mathrm{HSPF}=8.9 \\
\text { Cooling Cap }=24000 \mathrm{BTU} / \mathrm{hr}, \mathrm{SEER}=18.0\end{array}$ \\
\hline Green & Knoxville, TN & $\begin{array}{l}2300 \mathrm{ft}^{2} \\
\text { Two Story }\end{array}$ & $\begin{array}{l}\text { Ducted Inverter Mfr. A } \\
\text { Heating Cap=33400 BTU/hr, HSPF=13.0 } \\
\text { Cooling Cap=35000 BTU/hr, SEER }=20.5\end{array}$ \\
\hline
\end{tabular}




\section{ANALYSIS APPROACH}

The analysis of this report will be broken down into two sections, energy use analysis and efficiency analysis. The energy use analysis will focus on two of the research houses in the Campbell Creek subdivision and compare the weather normalized energy use of the variable capacity heat pump systems to the prior heat pumps that were installed in their respective houses. This allows for direct energy savings comparison of the ducted inverter heat pumps to single speed heat pumps. The efficiency analysis section will discuss the calculated efficiencies of the four variable capacity systems as well as differences in how these heat pumps operate and how their efficiency varies with average outdoor air temperature (OAT) and output capacity.

\section{ENERGY USE ANALYSIS}

For two of the research houses in the Campbell Creek subdivision, energy use data are available for both the new variable capacity heat pumps and the originally installed heat pumps. This allows for a direct comparison of the variable capacity heat pumps to the prior systems installed in their respective houses by plotting the energy use against the OAT.

\subsection{CC2}

In January 2012, a ducted inverter heat pump with zoning was installed in CC2. The system is rated at 3tons of cooling with an Air-Conditioning, Heating, and Refrigeration Institute (AHRI) rated Seasonal Energy Efficiency Ratio (SEER) of 20.5 and Heating Seasonal Performance Factor (HSPF) of 13.0. The fan coil was installed in the sealed attic and connected to the existing ductwork. The system had two zones, one upstairs and the other the downstairs.

The original system was a single-stage, 16 SEER, 9.75 HSPF, 3-ton heat pump that was zoned in the same fashion as the Mfr. A unit.

\subsubsection{Heating Data}

The heating data included in this section spans from 1/16/2012 to 4/1/2012 for the Mfr. A system and from $12 / 1 / 2009$ to $1 / 12 / 2011$ for the baseline system. In Figure 1, the daily energy use of the Mfr. A system is plotted against the average OAT and a curve fit is used to represent the average values. Because the Mfr. A system has a variable-speed compressor that can run at higher speeds when the OAT is lower, it can significantly reduce the need for resistance heat as supplemental heat. The weather was fairly mild during the operation of the Mfr. A system, but it still did a very good job of minimizing the need for resistance heat when compared to the baseline heat pump as seen in Figure 2. Most of the resistance heat use for the Mfr. A system was during defrost cycles, when the resistance heat was used to prevent cold air from being blown into the house. Because of the mild winter, the data do not provide a complete picture of the very-low-temperature resistance heat use of the Mfr. A system, but there is a substantial reduction $(\sim 66 \%)$ at temperatures down to $25^{\circ} \mathrm{F}$. Figure 3 shows the predicted average energy use of the Mfr. A ducted inverter system compared with the prior system across a range of OATs; the Mfr. A system shows 
significant energy savings. When these data are normalized by applying them to typical meteorological year (TMY) data for Knoxville, Tennessee, the Mfr. A system is predicted to save $1519 \mathrm{kWh}(32 \%)$ over the prior heat pump during a typical heating season. This is slightly more than the $25 \%$ savings that the HSPF ratings would indicate.

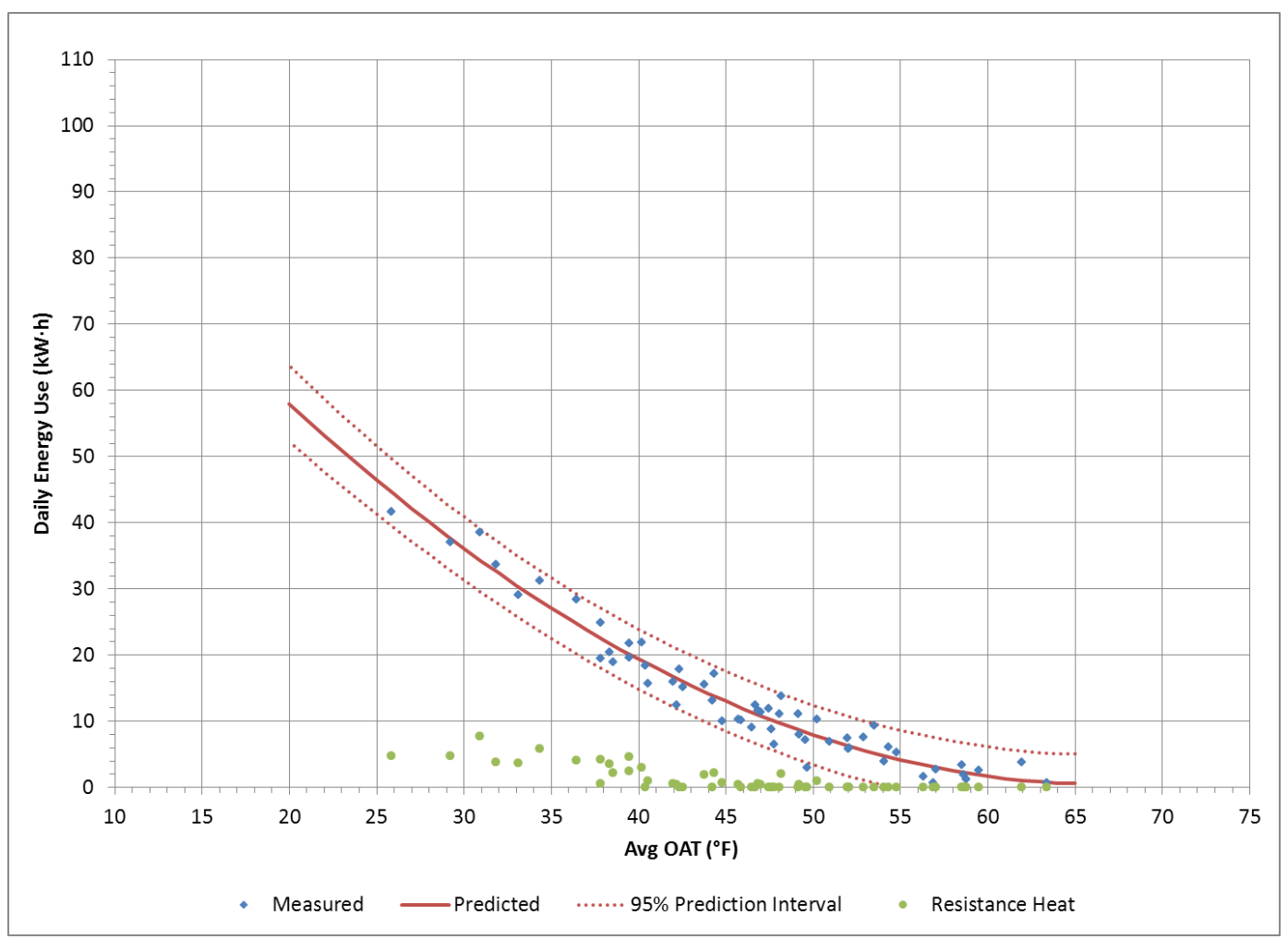

Figure 1. CC2 ducted inverter A heating data 


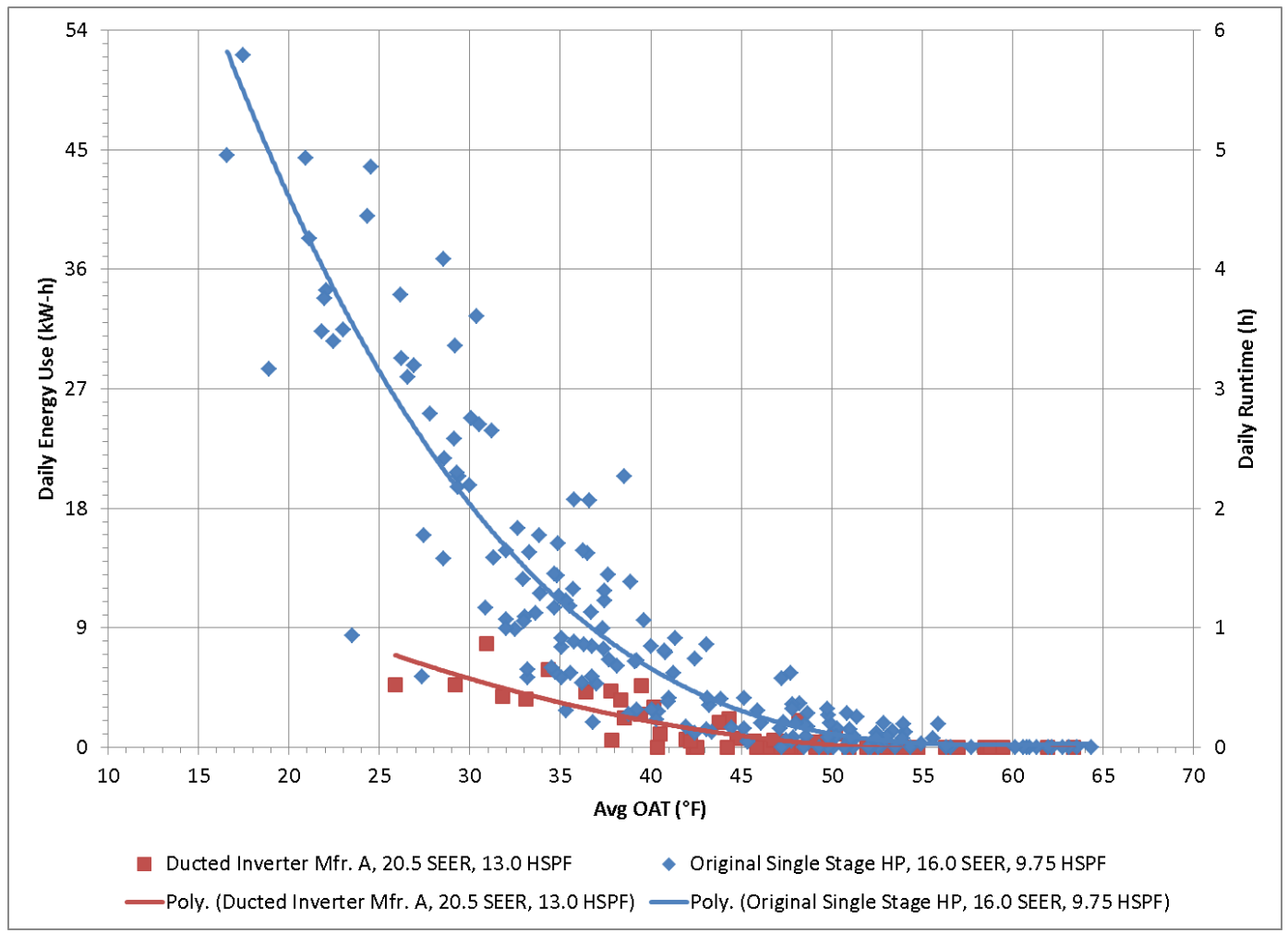

Figure 2. CC2 resistance heat use

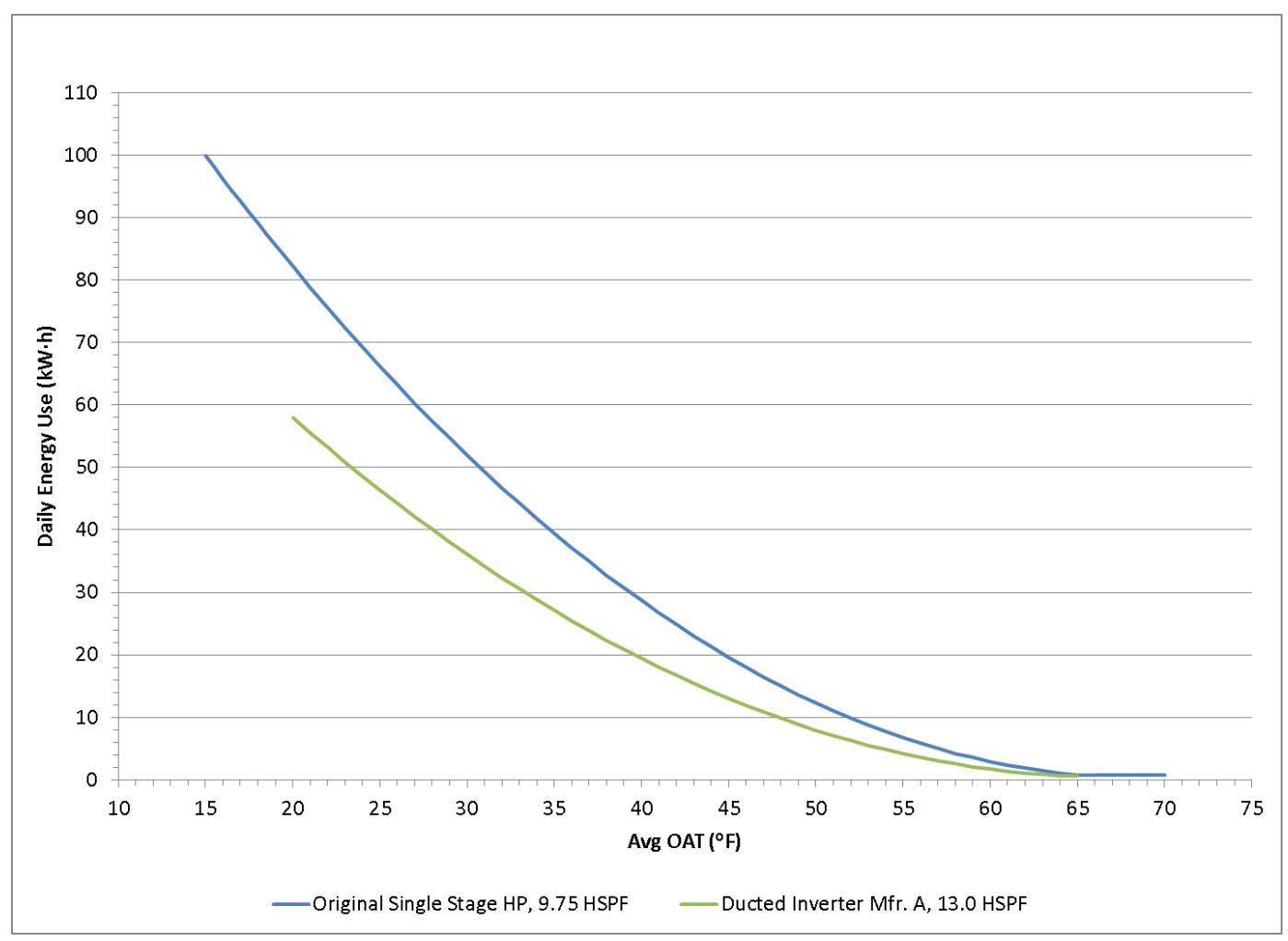

Figure 3. CC2 heating mode predictions 


\subsubsection{Cooling Data}

The cooling energy use for the Mfr. A system from 4/1/2012 to 9/30/2012 is plotted in Figure 4. The cooling data show very low energy use, with about a $\$ 2 /$ day energy cost for cooling at $\$ 0.10 / \mathrm{kWh}$ during the hottest days. Figure 5 shows the energy use compared with the baseline system. As with the heating season, the new ducted inverter system also showed significant energy savings during the cooling season. Normalizing the data to the TMY data for Knoxville predicts that the ducted inverter system will save 681 $\mathrm{kWh}(36 \%)$ compared to the baseline system. This is significantly more than the $22 \%$ savings predicted by comparing the SEER ratings of the two units.

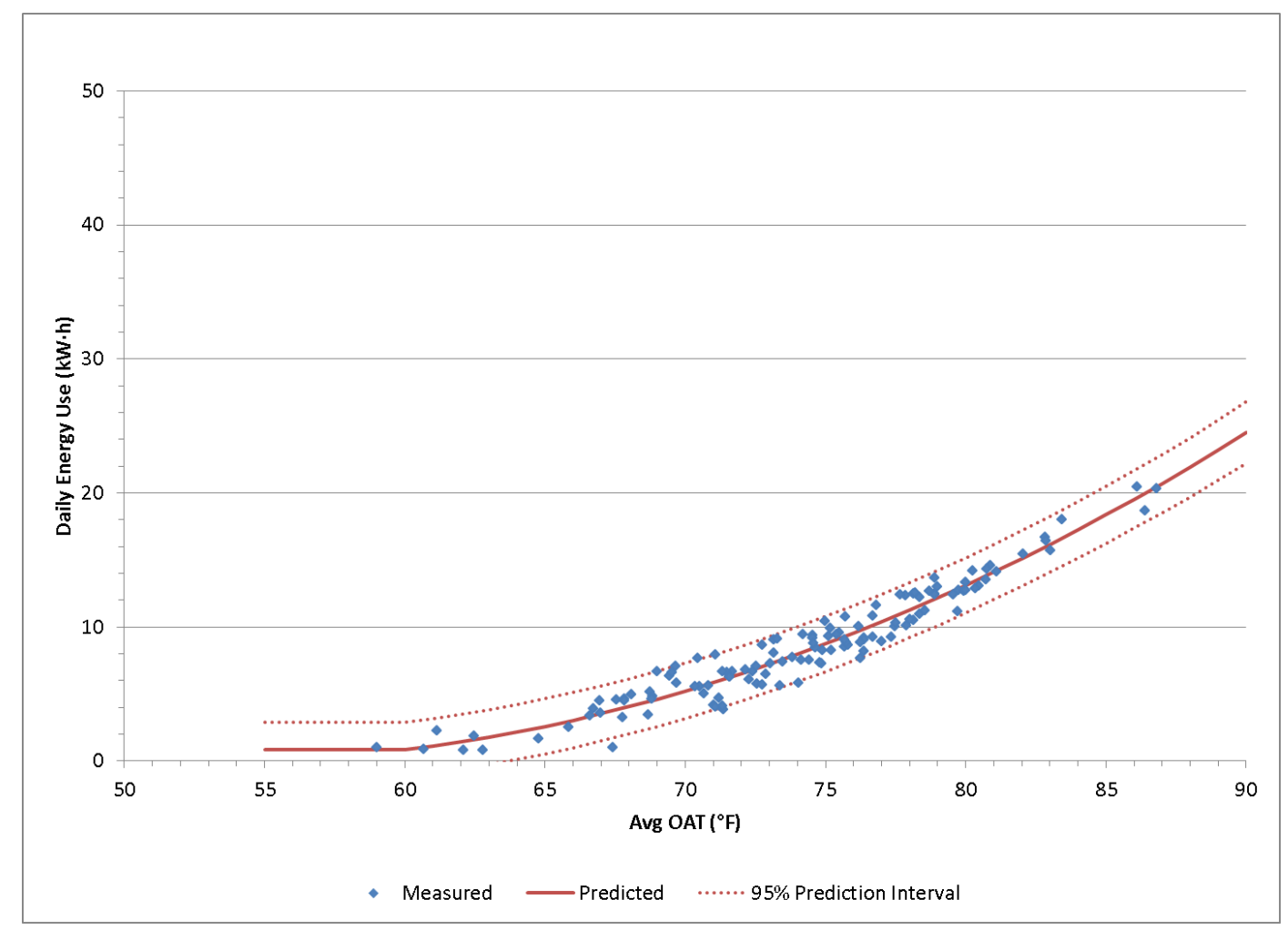

Figure 4. CC2 ducted inverter A cooling season data 


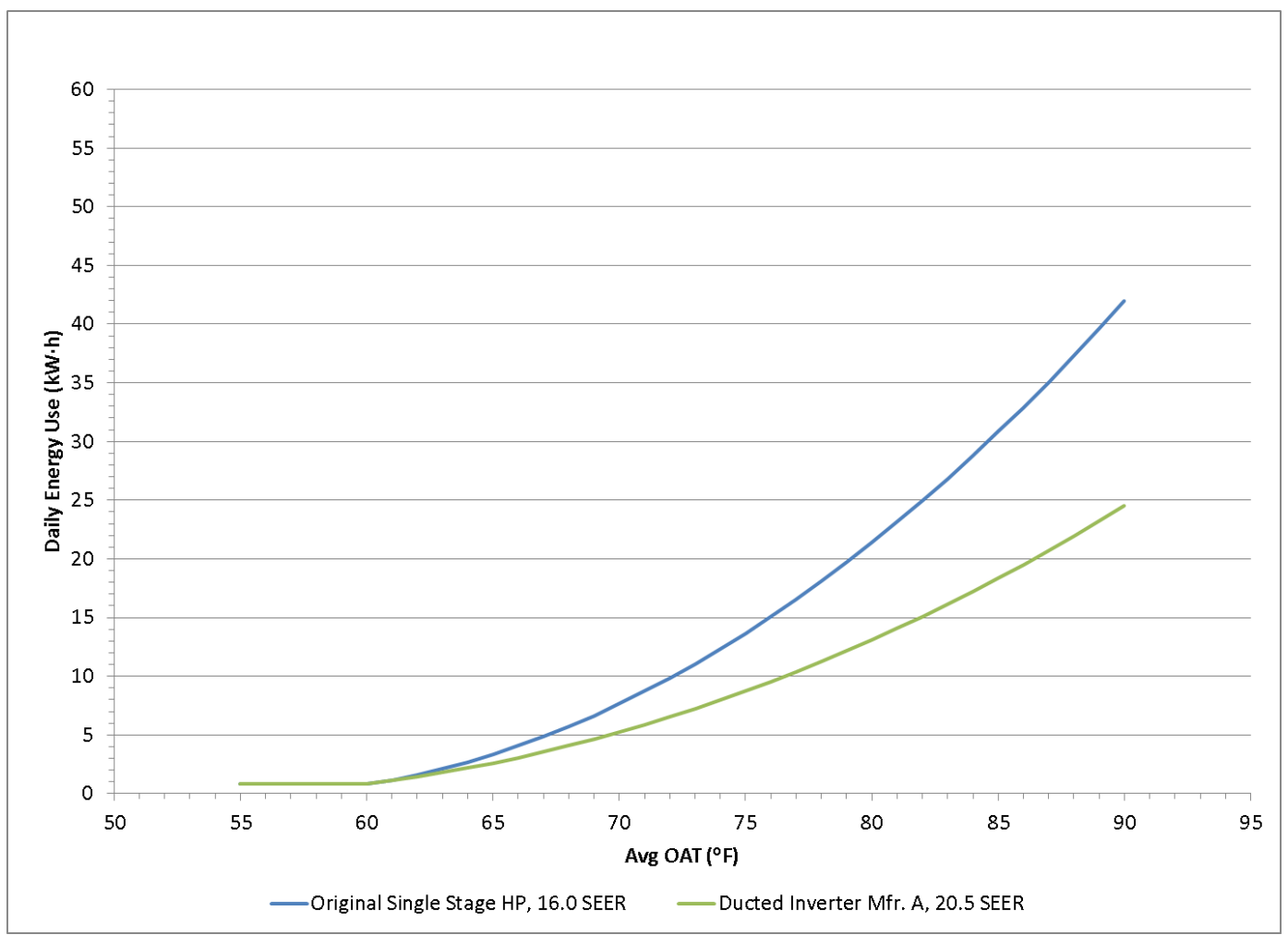

Figure 5. CC2 cooling mode predictions

\subsubsection{Annual Performance}

The TMY predictions for the heating and cooling season energy use are combined for an annual energy use comparison in Figure 6. Heating energy use was between 2.5- and 3-times more than the cooling season energy use for all systems. The ducted inverter system shows an annual savings of $2200 \pm 144$ $\mathrm{kWh}$, or $33 \%$, over the baseline system. 


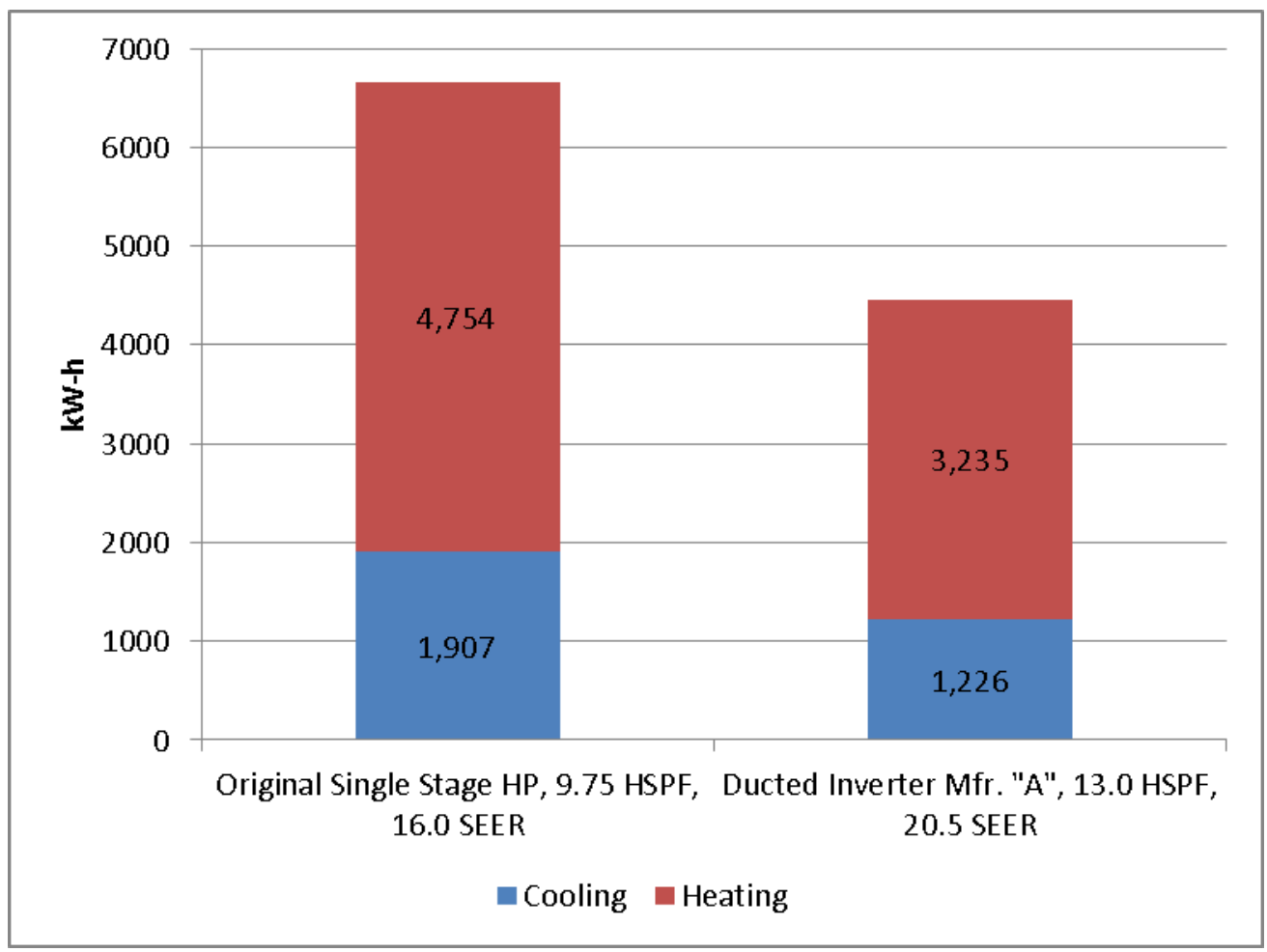

Figure 6. CC2 predicted TMY energy use for Knoxville, Tennessee

\subsubsection{CC3}

The ducted inverter, 18.0 SEER, 8.9 HSPF, 2-ton heat pump has been installed since December 2010. The fan coil is installed in a utility closet on the first floor instead of the attic as in CC2. There was no compatible zone control for the system, so it is set up as a single zone with the thermostat located centrally on the first floor. The original system was a two-stage, 16.0 SEER, 9.5 HSPF, 2-ton heat pump with zoning.

\subsubsection{Heating Data}

The heating energy use for the ducted inverter system from 2011 and 2012 is plotted in Figure 7. The new data match very well with the older data and indicate that the unit performance has not changed significantly. Late in February, representatives from Mfr. B visited to investigate concerns that the unit was not modulating as expected. This concern was documented in a prior report, Munk (2012), in which the unit was shown to run at near constant power throughout each cycle. During the visit, the refrigerant charge was checked and an additional 14 ounces was added to the system. No other issues were discovered during the visit. Given the limited heating data following the visit, there was not sufficient data to determine if the charge adjustment had any impact on the heating performance. Unlike the ducted inverter system from Mfr. A at CC2, the system from Mfr. B does not use resistance heat during defrost cycles. Therefore, system B did not use any resistance heat between 10/2011 and 9/2012. 


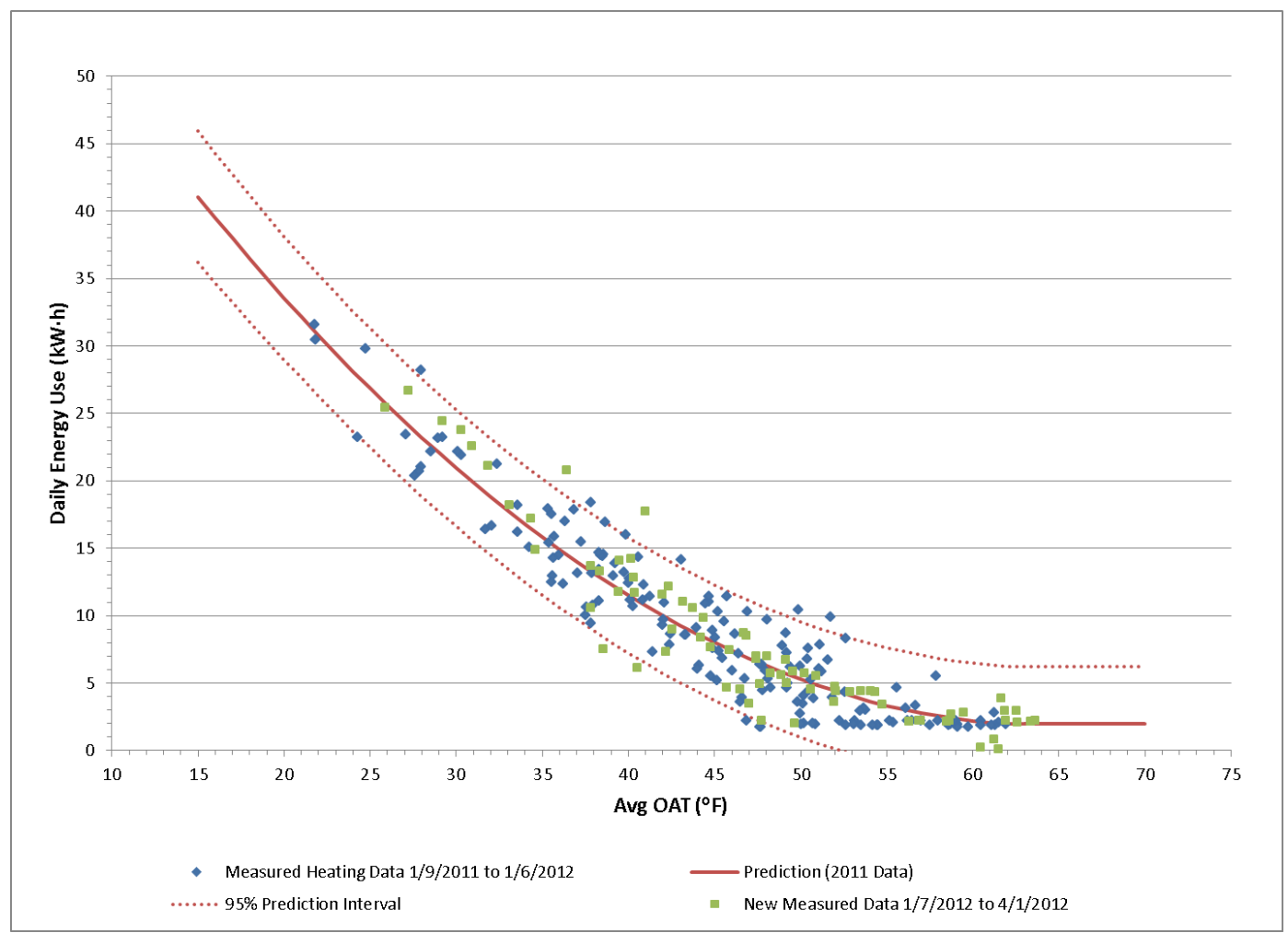

Figure 7. CC3 ducted inverter B heating season

Due to an error in the thermostat setup, the original two-stage heat pump was only allowed to run in the low stage during the heating season. In order to make up for this loss in heating capacity, the system used more resistance heat than expected. There is no simple way to correct the data for this issue, so instead a minimum and maximum energy use will be presented to provide bounds for the performance of a properly installed unit. The maximum energy use is defined by the raw data with excessive resistance heat use. The minimum energy use is calculated by removing all of the resistance heat energy use, including during defrost, and adding back in this energy after dividing by the rated HSPF of 9.5. Since this method eliminates all resistance heat energy during defrost and credits the unit with the rated HSPF even at very low temperatures where the bulk of the resistance heat use occurs, it is a conservative minimum bound. As seen in Figure 8 though, the ducted inverter system still used less energy than the minimum bound of the baseline two-stage HP. The difference in standby power use of the two systems is also evident in this figure, with the ducted inverter system using about $2 \mathrm{kWh} /$ day or $83 \mathrm{~W}$. 


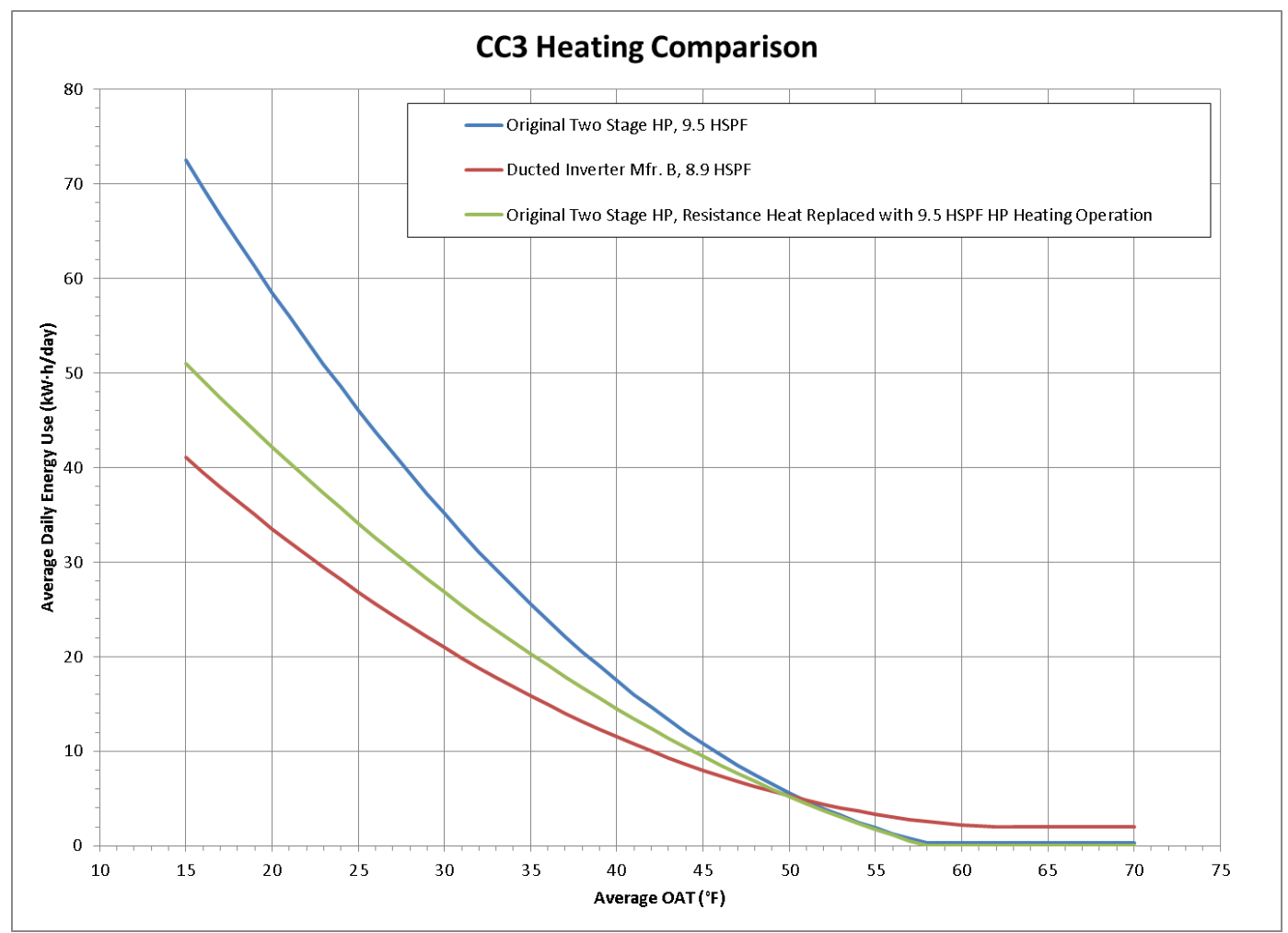

Figure 8. CC3 heating comparison

\subsubsection{Cooling Season}

Since the ducted inverter system does not have zoning capability, the existing zone dampers and room registers are adjusted seasonally to maintain similar temperatures on the first and second levels. During the summer, the downstairs requires significantly less cooling than the upstairs; so to achieve a reasonable temperature balance, the downstairs damper was closed completely. Although the arrangement provided consistent temperatures, it had the unintended effect of reducing the system airflow. The fan coil does have a variable-speed BPM motor; however, closing the downstairs damper increased the external static pressure enough that the motor was no longer able to maintain the desired airflow. When the issue was discovered, the reduced airflow was measured and the damper was opened enough to allow the motor to reach the target airflow. For analysis, the data were separated into two sets, one with the downstairs damper partially open and the other with the downstairs damper closed, as seen in Figure 9. These two data sets from the 2012 cooling season were compared with the data from the 2011 heating season. The 2012 data indicate slightly worse performance at lower average OATs and slightly better performance at higher OATs. The data falls within the $95 \%$ confidence prediction intervals that were generated from the 2011 data. 


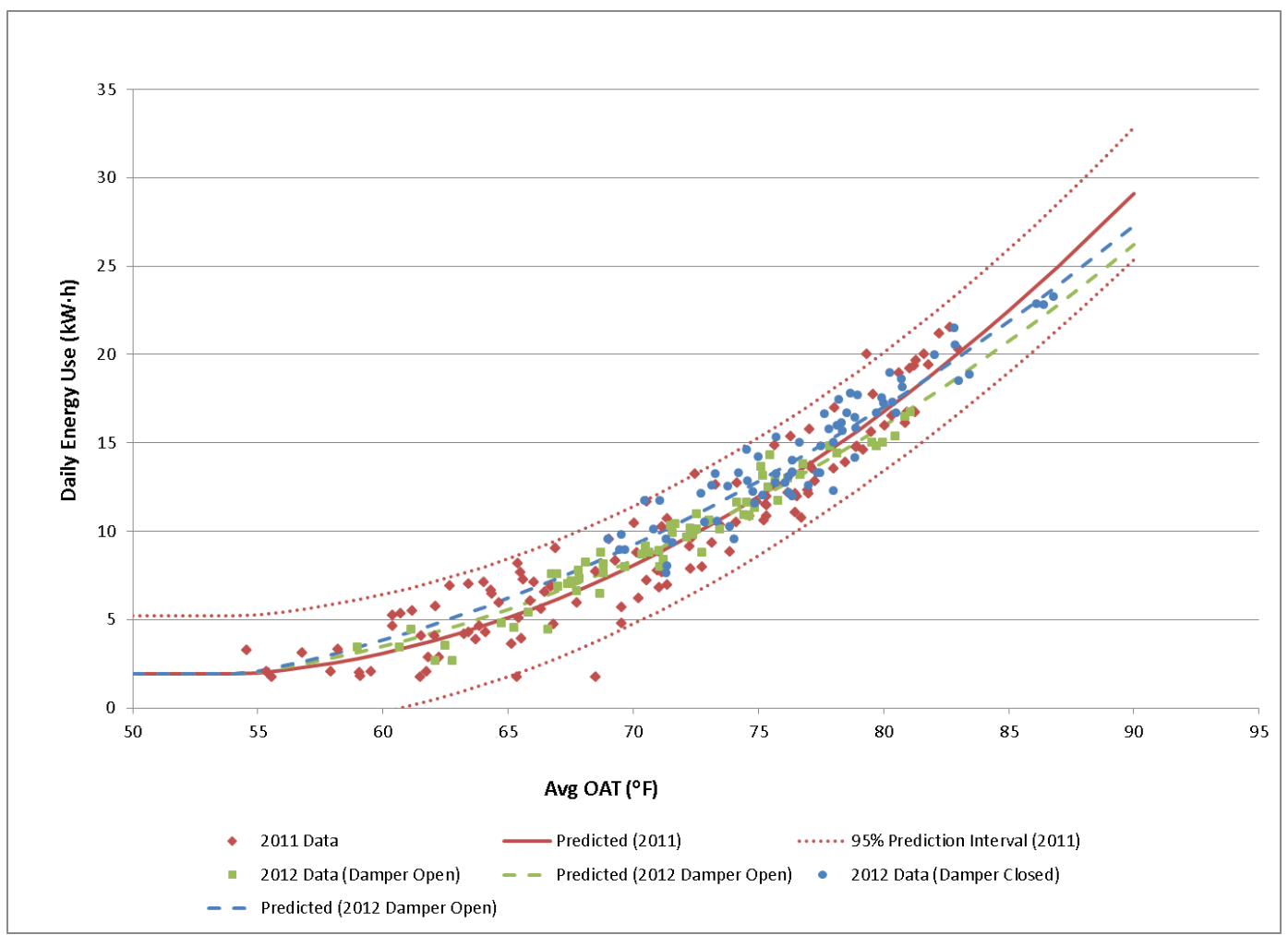

Figure 9. CC ducted inverter B cooling season data

The damper-open and damper-closed data sets were analyzed and predictions were generated for the entire 2012 cooling season for both sets. These were compared in order to determine if the difference in the data sets was statistically significant and, if so, the magnitude of the difference. The predicted energy difference indicated that with the downstairs damper closed, the system would have used $137 \pm 40 \mathrm{kWh}$ more energy (with $95 \%$ confidence) than if the damper was only partially open and the blower could reach the target airflow. This translates into a $7.6 \% \pm 2.2 \%$ increase in energy use. This is only a modest penalty for what was a significant, $\sim 38 \%$, reduction in airflow. Figure 10 and Figure 11 show a comparison between the compressor power and sensible heat ratio (SHR) plotted versus OAT for periods when the downstairs damper was partially open and periods when it was fully closed. The plots show a significant decrease in compressor power when the damper was closed, but the SHR was virtually the same. For the SHR to be the same, the total cooling capacity had to have been reduced by approximately the same percentage that the airflow was reduced. The drop in compressor power indicates that the reduced capacity was likely a result of the variable-speed compressor running at lower speeds. It is likely that the system reduced the compressor operating speed in response to the reduced airflow caused by the downstairs damper being closed. The net result was reduced capacity and only slightly reduced performance. 

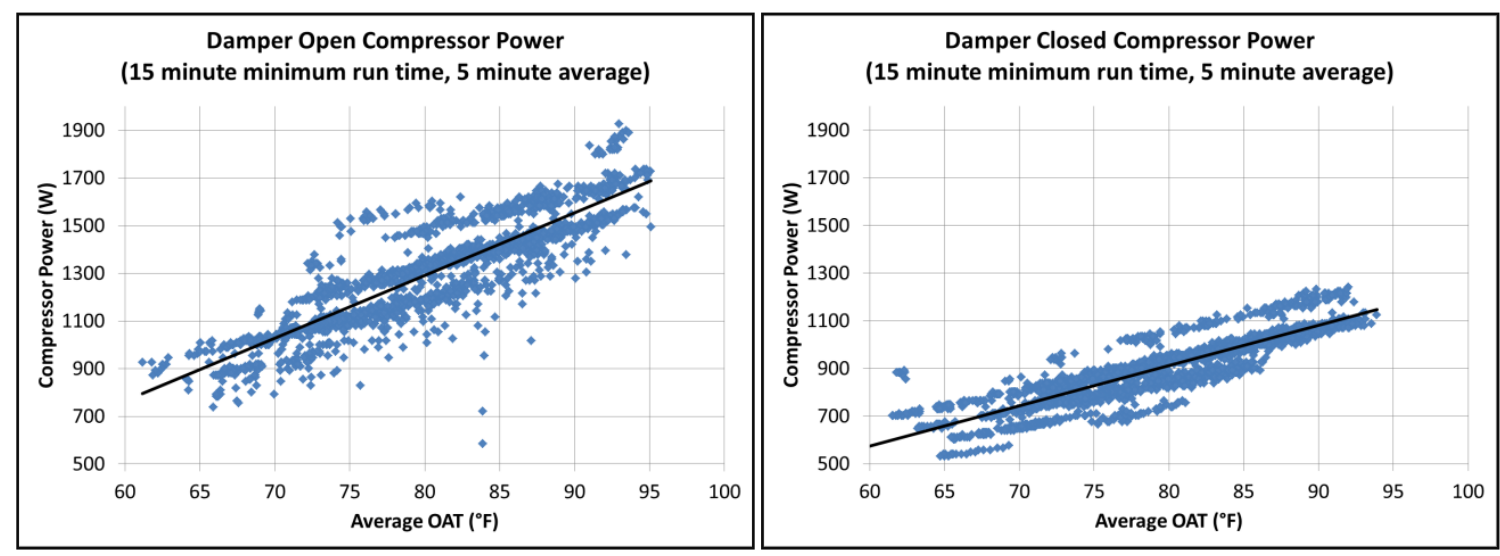

Figure 10. CC3 compressor power comparison
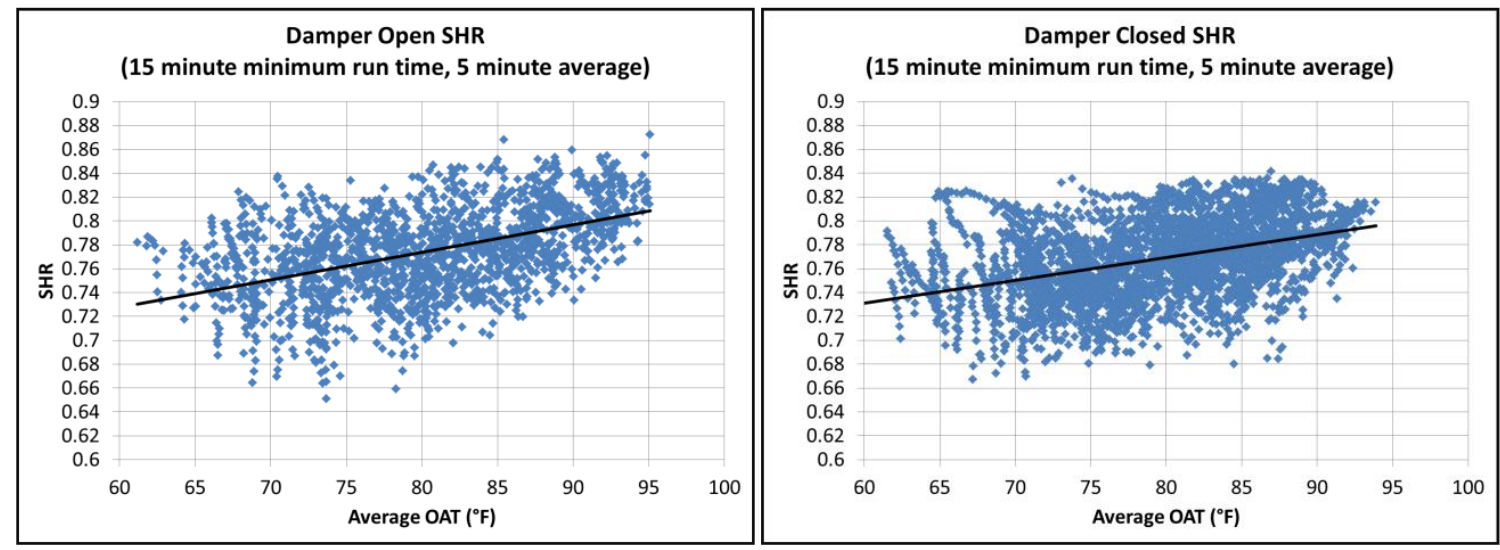

Figure 11. CC3 SHR comparison

Unlike with the heating season, the ducted inverter system B performance in the cooling season was worse than the original system, Figure 12. CC3 cooling season comparison. This is surprising given the fact that the original system is rated at 16.0 SEER and the Mfr. B system was rated at 18.0 SEER. Applying the energy use curve fits to TMY data for Knoxville predicts that the Mfr. B system would use $306 \mathrm{kWh}$ (23\%) more energy than the baseline system despite the SEER ratings indicating that the Mfr. B system should save $11 \%$. 


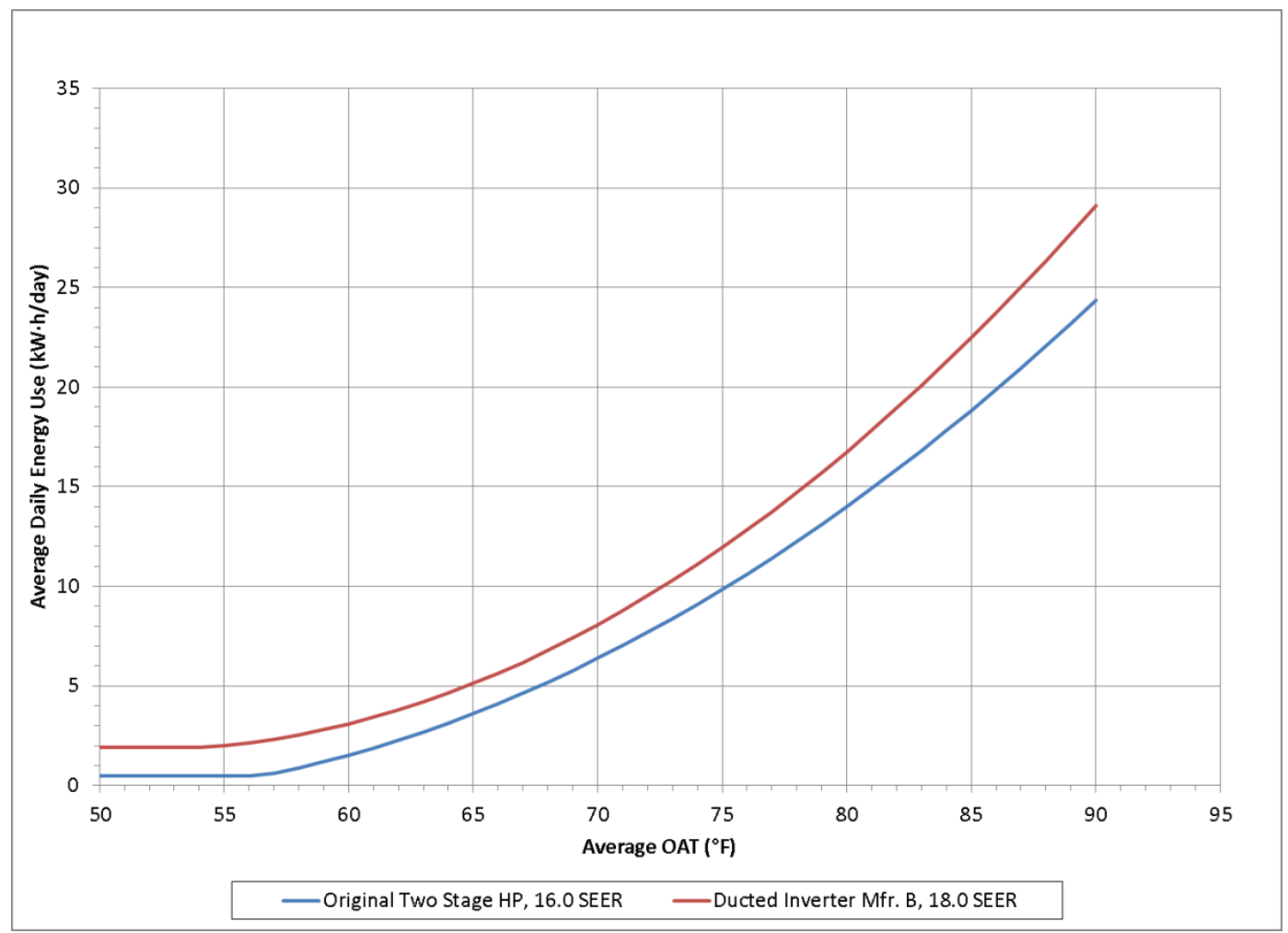

Figure 12. CC3 cooling season comparison

\subsubsection{Annual Performance}

The TMY predictions for the heating and cooling season energy use are combined for an annual energy use comparison, Figure 13. Both raw data and the corrected data for the heating energy use of the baseline system are shown. As stated earlier, the corrections are likely overcorrecting the for the resistance heat energy use. Therefore, it is safe to say that the heating energy use of a properly installed unit would fall between the raw data and corrected data. Therefore the ducted inverter system saved between $11 \%$ and $30 \%$ of energy use in the heating season. This however was offset by the increased energy use in the cooling season. 


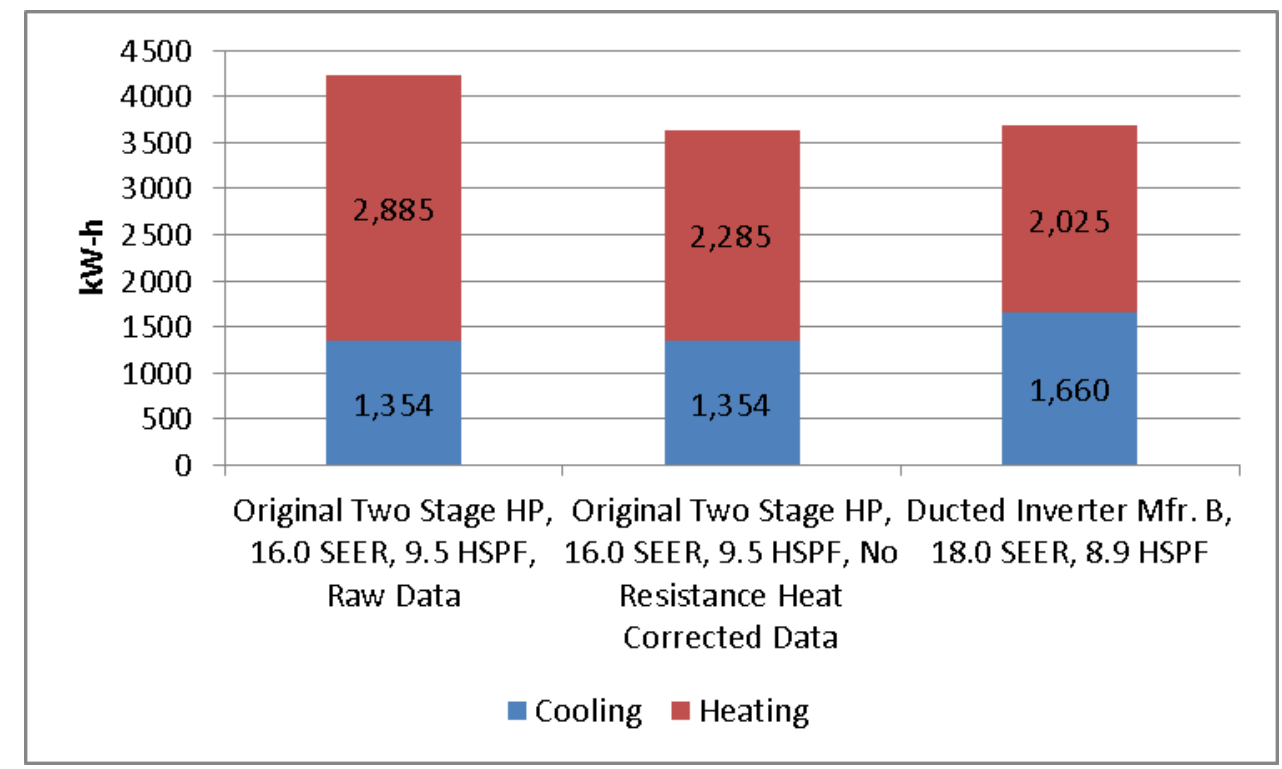

Figure 13. CC3 predicted TMY energy use for Knoxville, Tennessee

\section{EFFICIENCY ANALYSIS}

In addition to looking at the energy use, the capacity and efficiency of the heat pumps were calculated. The details of these calculations and the measurements used in them are detailed in the Appendix.

An item of interest with variable speed heat pumps is how they operate and cycle in order to meet the load. With the capability to run at lower speeds, variable speed units can decrease cycling losses and provide more consistent temperatures in the home. Reduced capacity operation also allows the unit to take advantage of comparatively larger heat exchangers. This should result in more efficient operation at lower speeds.

In order to determine the trends in efficiency with respect to OAT and capacity, the heating and cooling data from each variable speed unit were plotted on a separate color map. The operating capacity is plotted as a percent of the AHRI rated capacity on the vertical axes and the OAT is plotted on the horizontal axes. The colors of the data squares indicate the average efficiency of all data points that fall within those operating conditions. The percentages within the squares show the percentage of the total runtime that occurred at these conditions, with only values over $1 \%$ being shown. Along the right hand side of the plot are percentages of the total runtime that occurred at each percent of rated capacity range. To reduce the impact of transient data during startup, the data was filtered to only include data in which the unit had been running for at least 15 minutes.

The fact that we have two identical systems from two different manufacturers, with one of each installed in unoccupied research houses with simulated occupancy and the others installed in occupied houses, provides a unique opportunity to verify trends in the data and observe the impact of real human behavior on the data. 


\subsection{HEATING SEASON}

The measured performance of the four inverter driven heat pumps and two baseline heat pumps is summarized in Table 2. The heating efficiency of a unit will vary based on the OAT, return air temperature, airflow, cycle length, and, for systems with inverter driven compressors, compressor speed. The date ranges of the collected data vary substantially, which is also reflected in the average OATs. The average HSPF from the measured data is presented along with the uncertainty that is propagated from sensor uncertainty (example in Appendix). In order to compensate for differences in OAT, the efficiency for each unit was normalized by taking the percent of delivered load weighted average of the energy input ratio (EIR) for each temperature bin from the AHRI HSPF rating (see Appendix for more details). This allows a more direct comparison with the rated HSPF and normalizes the data sets for OAT (details in the Appendix). This does not compensate for cycling losses due to units being sized differently relative to their respective building load. The two Mfr. A systems performed below their rated HSPF. The limited heating data for the Green house resulted in only mild weather data, as indicated by the higher average OAT, which inflates this unit's efficiency and did not provide enough data to accurately normalize it as was done with the other units. Slightly offsetting the milder weather was the fact that the unit used a substantial amount of resistance heat while recovering from a vacation setback. The CC2 unit's normalized HSPF was $36 \%$ lower than the AHRI rated HSPF. The Mfr. B systems also performed at lower efficiencies than their rated HSPF although by smaller margins, $11 \%$ and $16 \%$. The units had very similar efficiency in the heating mode despite very different operating behavior that will be discussed in a later section. For reference the two single-stage heat pumps installed at $\mathrm{CC} 1$ can be compared. These units also performed well below their rated efficiency, $32 \%$ and $22 \%$, which indicates that measured efficiencies lower than the rated HSPFs are not unique to variable speed equipment. 
Table 2. Heating Season Efficiencies

\begin{tabular}{|c|c|c|c|c|c|c|c|}
\hline & \multicolumn{7}{|c|}{$\%$} \\
\hline & $\begin{array}{c}\text { Published } \\
\text { HSPF }\end{array}$ & $\begin{array}{c}\text { Average } \\
\text { HSPF } \\
\text { From } \\
\text { Available } \\
\text { Test Data }\end{array}$ & $\begin{array}{c}\text { OAT } \\
\text { Normalized } \\
\text { HSPF From } \\
\text { Test Data }\end{array}$ & $\begin{array}{c}\text { Difference } \\
\text { of } \\
\text { Normalized } \\
\text { HSPF from } \\
\text { Published } \\
\text { HSPF }\end{array}$ & $\begin{array}{c}\text { Average } \\
\text { OAT } \\
\text { during } \\
\text { runtime }\end{array}$ & $\begin{array}{c}\text { Average } \\
\text { Return Air } \\
\text { Temperature } \\
\pm 2 \sigma\end{array}$ & $\begin{array}{l}\text { Date } \\
\text { Range }\end{array}$ \\
\hline \multicolumn{8}{|l|}{ Heat Pump } \\
\hline CC1 HP1 & 7.7 & $5.8 \pm 1.0$ & 5.2 & $-32 \%$ & 35.9 & $68.4 \pm 2.2$ & $\begin{array}{l}11 / 1 / 2011 \\
\text { to } \\
3 / 15 / 2012\end{array}$ \\
\hline CC1 HP2 & 7.7 & $6.6 \pm 1.1$ & 6.0 & $-22 \%$ & 34.7 & $70.1 \pm 5.4$ & $\begin{array}{l}11 / 1 / 2011 \\
\text { to } \\
3 / 15 / 2012\end{array}$ \\
\hline $\begin{array}{l}\mathrm{CC} 2 \\
\text { (Ducted } \\
\text { Inverter A) }\end{array}$ & 13.0 & $9.5 \pm 1.6$ & 8.3 & $-36 \%$ & 36.8 & $72.0 \pm 3.0$ & $\begin{array}{l}2 / 6 / 2012 \text { to } \\
3 / 13 / 2012\end{array}$ \\
\hline $\begin{array}{l}\text { Green } \\
\text { (Ducted } \\
\text { Inverter A) }\end{array}$ & 13.0 & 11.2 & N/A & N/A & 45.1 & $68.5 \pm 3.2$ & $\begin{array}{l}3 / 8 / 2012 \text { to } \\
4 / 22 / 2012\end{array}$ \\
\hline $\begin{array}{l}\mathrm{CC} 3 \\
\text { (Ducted } \\
\text { Inverter B) }\end{array}$ & 8.9 & $8.1 \pm 1.3$ & 7.9 & $-11 \%$ & 33.6 & $71.1 \pm 2.9$ & $\begin{array}{l}1 / 18 / 2012 \\
\text { to } \\
3 / 11 / 2012\end{array}$ \\
\hline $\begin{array}{l}\text { Lake } \\
\text { (Ducted } \\
\text { Inverter B) }\end{array}$ & 8.9 & 7.8 & 7.5 & $-16 \%$ & 43.9 & $72.8 \pm 3.2$ & $\begin{array}{l}1 / 10 / 2012 \\
\text { to } \\
3 / 13 / 2012\end{array}$ \\
\hline
\end{tabular}

\subsubsection{Ducted Inverter B Heating Operation}

Figure 14 shows the heating data of the ducted inverter B system installed at CC 3 . There are a few trends that are apparent from this plot. The most obvious and intuitive is that the unit provides heat more efficiently at higher OATs. This is typical of heat pumps because the higher OAT reduces the lift required to provide heat to the house. The next trend is that the unit is operating at higher capacities when the outdoor air temperature is higher. This is the sort of trend that would be expected from a fixed capacity HP where the OAT is the determining factor with regards to how much heating capacity the unit can deliver. The last trend is more subtle, but, at any given OAT, the unit is typically more efficient when operating at higher capacities. This is most obvious in the $21^{\circ} \mathrm{F}$ to $36^{\circ} \mathrm{F}$ range where there is wider spread in the percent rated capacity data. This trend is counterintuitive because of the fixed heat exchanger size. At lower capacities the comparatively larger heat exchangers should be more efficient. This effect could be due to the inverter and/or compressor operating less efficiently at lower speeds. 


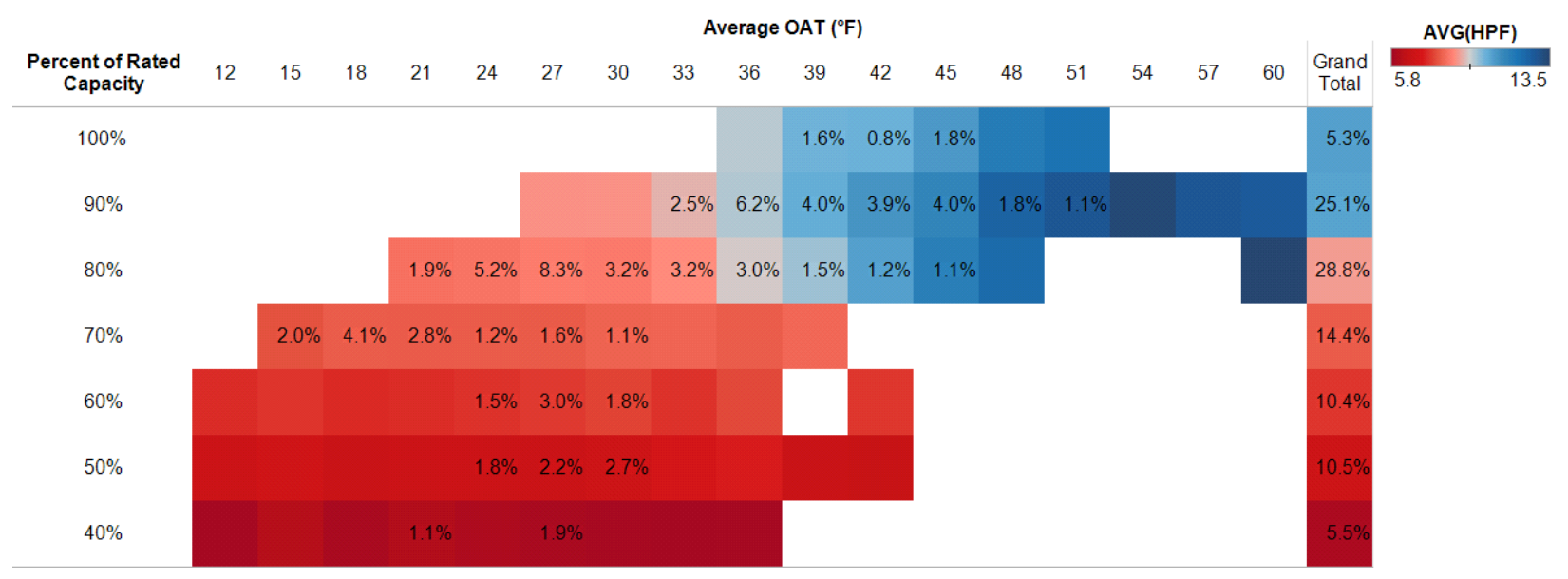

Figure 14. CC3 heating performance map

The Lake House had the same model and size heat pump installed as CC3, however this house was occupied. The color map, Figure 15, is not as clear as the one for CC3, which is likely due to the inconsistent behavior of real occupants. Unlike the unit at $\mathrm{CC} 3$, this unit ran at low capacity most of the time and only ran at higher capacities when it was very cold. This is the expected behavior of a variable speed heat pump that is controlling its speed in order to match the load on the house. When looking at individual rows, the dependence of efficiency on OAT can still be seen. As with the Mfr. B system at $\mathrm{CC} 3$, the unit appears to operate more efficiently at higher capacities, particularly at the lower OATs, although this is not as obvious as with the unit at CC3.

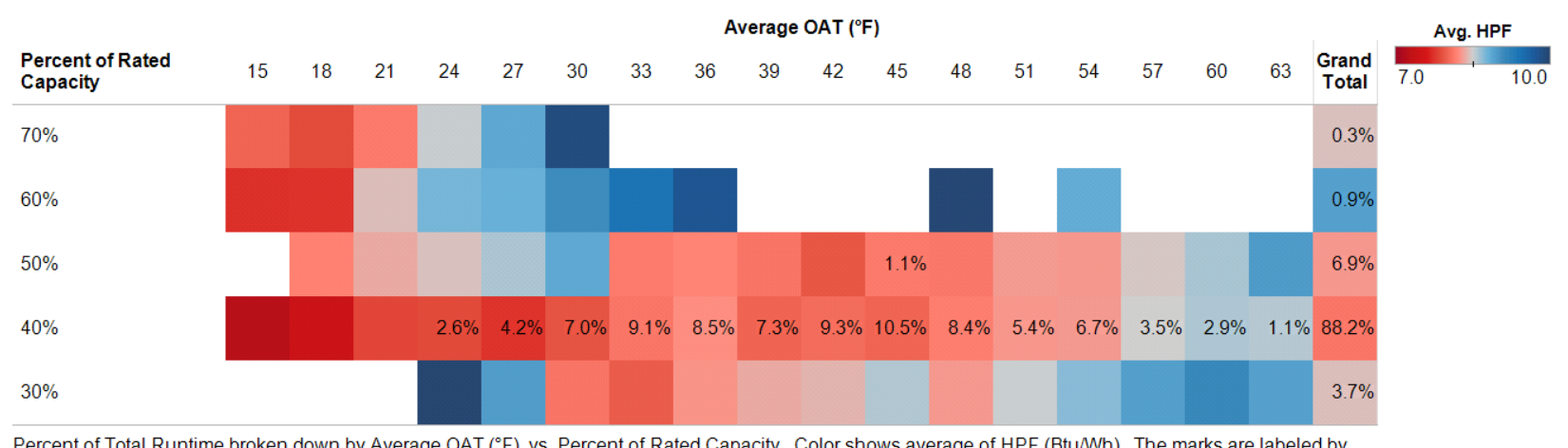

Percent of Tot Runtime broken down by Average OAT $\left({ }^{\circ} \mathrm{F}\right)$ vs. Percent of Rated Capacity Color shows average of HPF (Btu/Wh). The marks are labeled by percentage of Total Runtime.

Figure 15. Lake heating performance map

In order to determine if the difference in operating capacity range was due to the house that the unit was installed in, the delivered heating loads for each house are plotted on a daily basis, Figure 16 and Figure 17. As seen in the plots, the Lake House's heating load is over three times higher than CC3's especially at milder temperatures, but it generally operated at lower capacities. This means that the CC 3 unit ran at higher capacity, cycled more frequently, and had shorter average runtimes. These are generally undesirable characteristics in terms of comfort and efficiency. However, both ducted inverter B systems generally exhibited higher efficiency at higher capacities, which appears to have yielded better heating performance for the unit installed at CC3. 


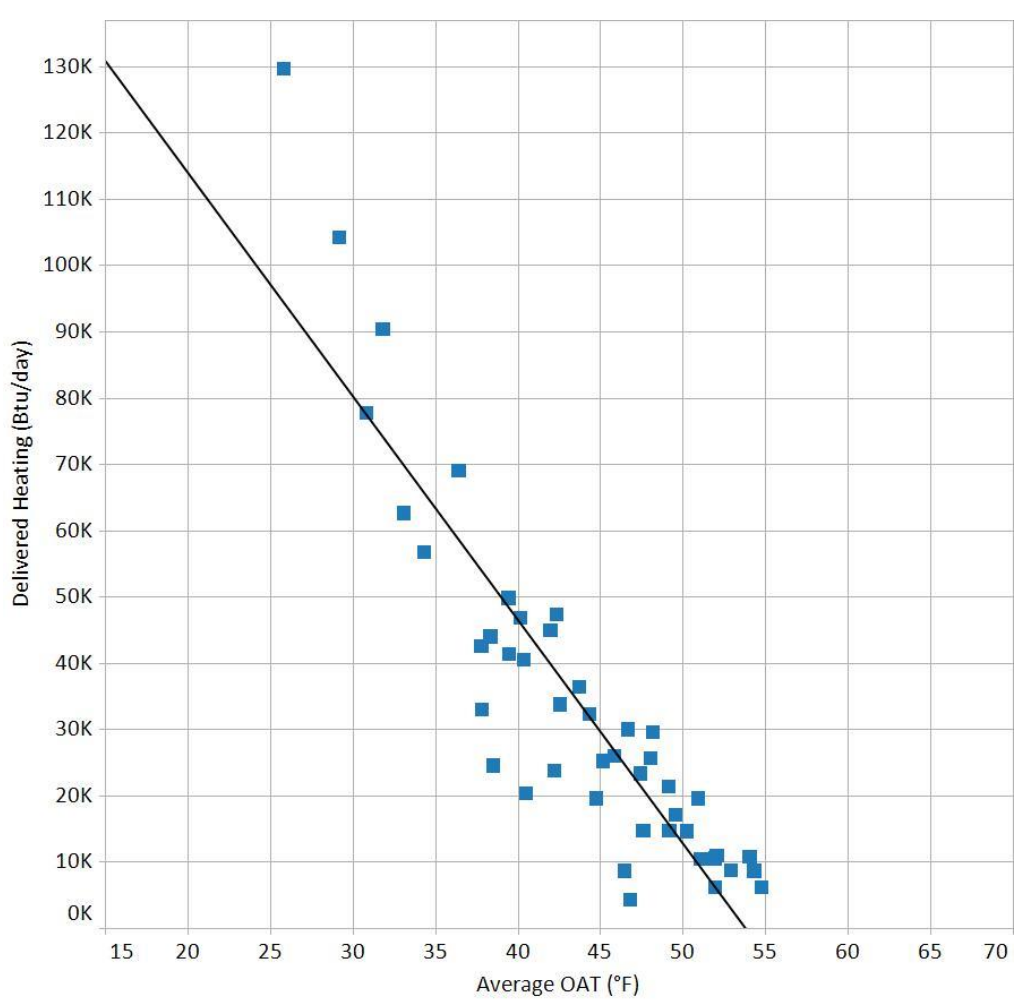

Figure 16. CC3 heating load

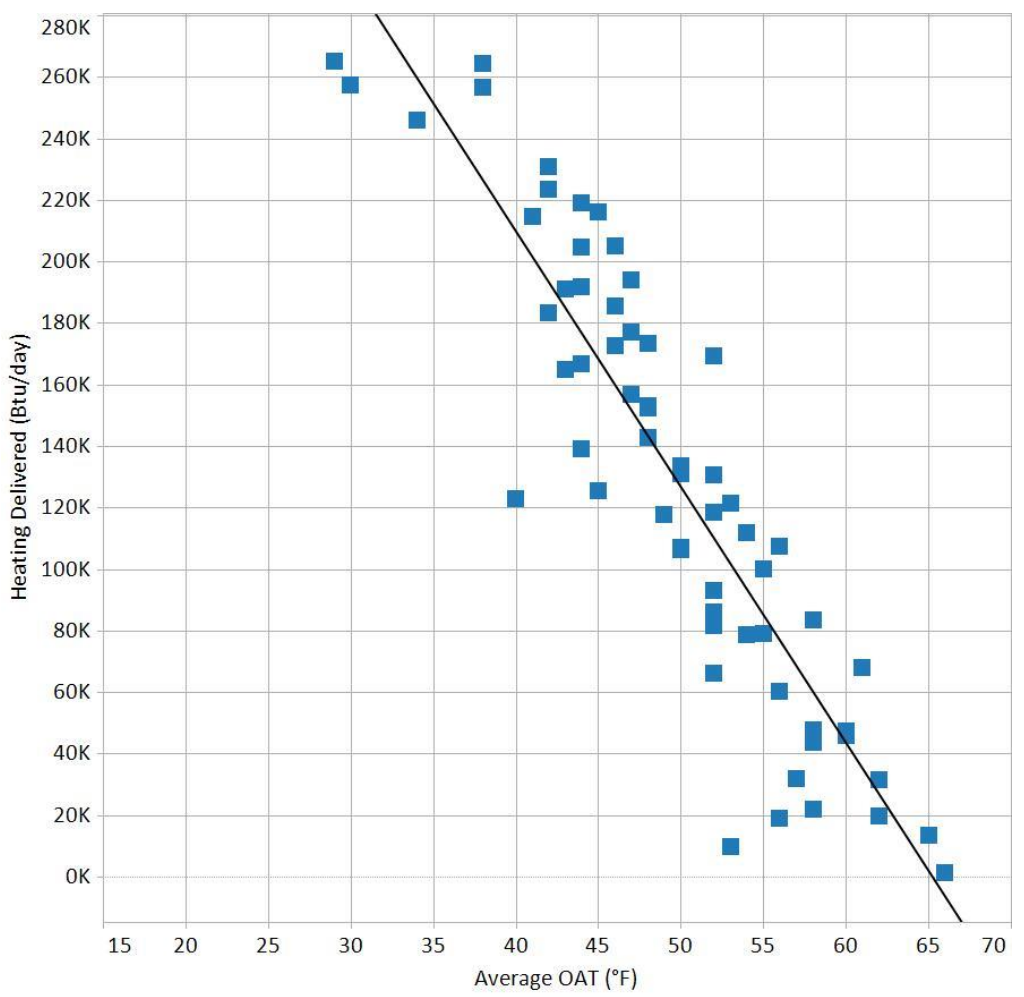

Figure 17. Lake heating load 


\subsubsection{Ducted Inverter A Heating Operation}

The heating season data for the ducted inverter A system at CC2 was analyzed in the same fashion with results in Figure 18. This unit exhibited the expected behavior of a variable capacity heat pump. During mild temperatures, the unit operated at low capacity, and as the temperature is reduced the unit runs at higher capacities in order to meet the higher heating load. As with the other heat pumps, the efficiency is strongly dependent on the OAT, which is seen by the red to blue trend from left to right. The unit also runs at higher efficiencies at lower capacities as seen by the trends in individual columns. This is intuitively what is expected since the ratio of the heat exchanger size to capacity is larger at lower capacity. As with the $\mathrm{CC} 3$ data, the $\mathrm{CC} 2$ data is very neat due to the absence of noise introduced by human occupants.

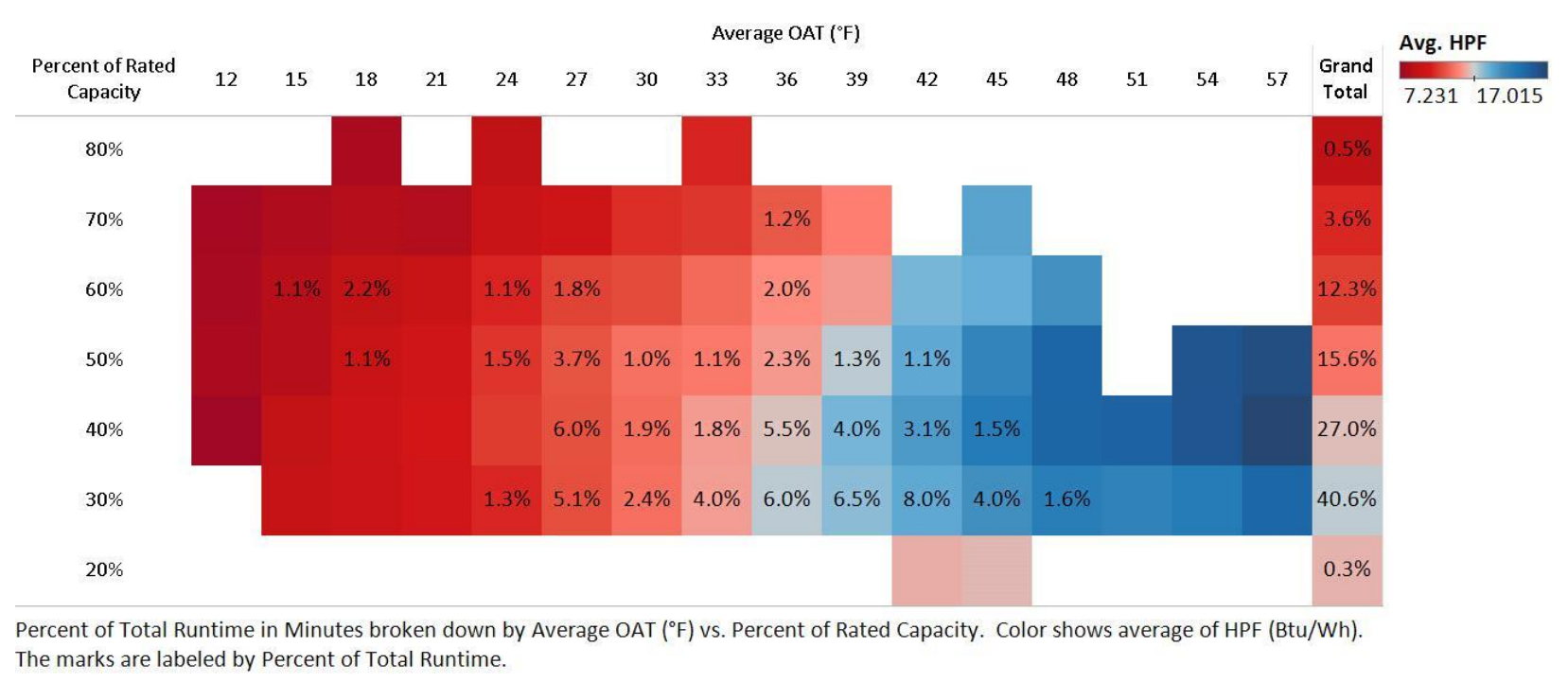

Figure 18. CC2 heating performance map

The heating load at CC2 is plotted in Figure 19 versus the daily average OAT. It is roughly twice that of $\mathrm{CC} 3$, however the unit at $\mathrm{CC} 2$ operated most of the time at lower absolute capacities than the CC3 unit despite having a higher rated capacity. 


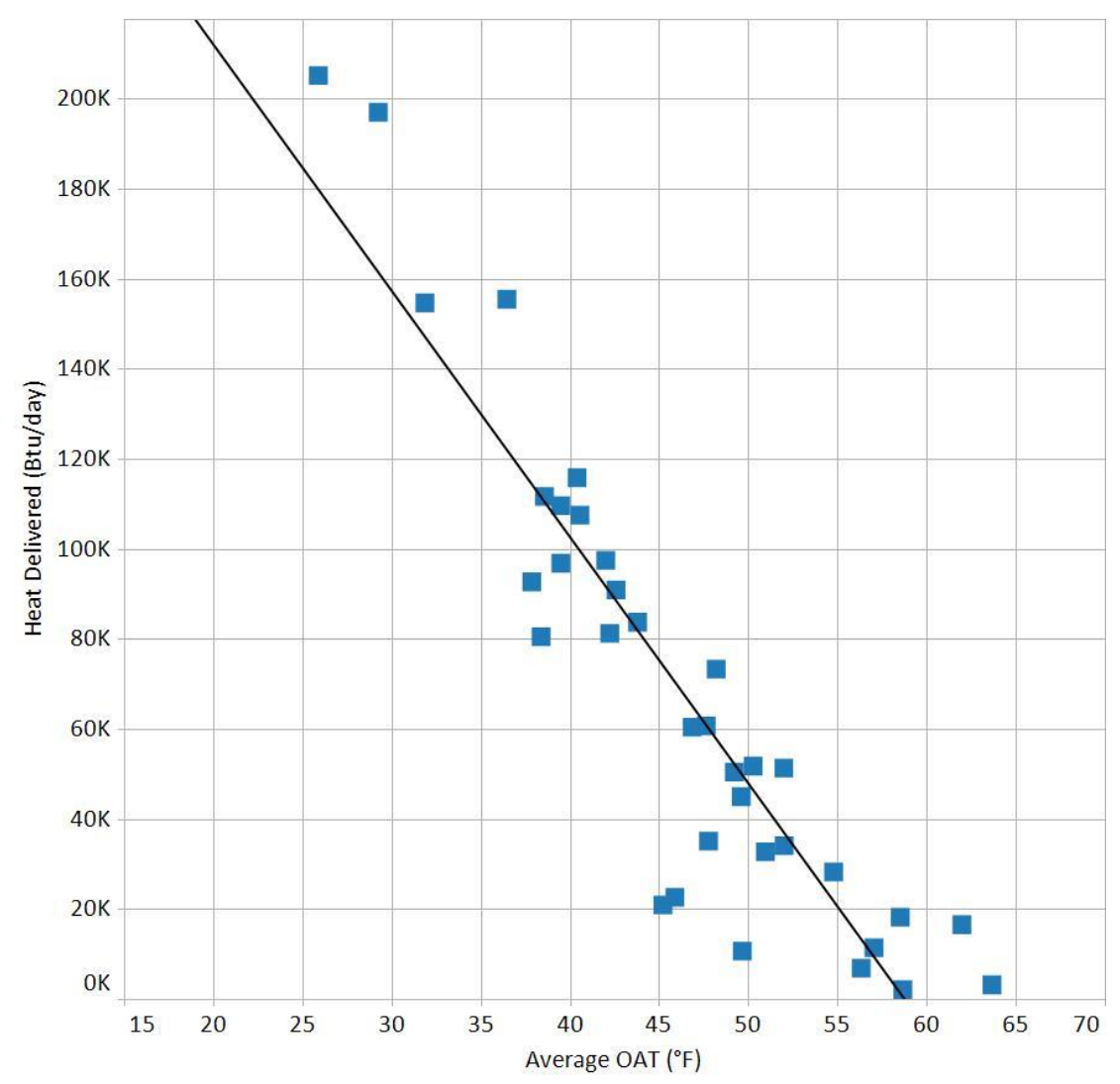

Figure 19. CC2 heating load

The ducted inverter system at the Green House only had limited heating season data and there were frequent changes to the thermostat set point by the homeowner. These issues made it difficult to clearly determine unit operating characteristics from the data.

\subsubsection{Cooling Season}

The measured performance of the four inverter driven systems and two baseline heat pumps installed at $\mathrm{CC} 1$ is summarized for the cooling season in Table 3 . The cooling efficiency of a heat pump will vary with OAT, return air temperature, return air humidity, airflow, cycle length, and, for systems with inverter driven compressors, compressor speed. As seen in the table, the average OAT, return air temperature, and return air humidity are relatively consistent between all of the homes and likely only have minor impacts on the performance differences seen between the units. The two occupied houses, Green and Lake, show much larger swings in return air temperature and humidity likely being caused by changes to the cooling set point. The unit at $\mathrm{CC} 2$ was run without relative humidity $(\mathrm{RH})$ control for the first month of the summer and with humidity control (with a setpoint of $46 \%$ in order to more closely match humidity levels in $\mathrm{CC} 1$ and $\mathrm{CC} 3$ ) during the rest of the summer. As with the heating data, the cooling data was normalized based on the SEER rating temperature bins and is discussed further in the Appendix. The measured performance for the two Mfr. A systems, when running without RH control, at CC2 and the Green House is between $9 \%$ and $18 \%$ less than the published SEER. The lower performance of the unit in the Green House can be attributed to the higher fan power consumption due to more restrictive ductwork. If the average fan efficiency from CC2 were applied to the Green House unit, then the 
resulting OAT normalized SEER would be $18.2 \mathrm{Btu} / \mathrm{Wh}$; $11 \%$ lower than the published SEER and very close to the performance of the $\mathrm{CC} 2$ unit without RH control. Enabling RH control on the unit at CC2 reduced the OAT normalized SEER of the system by $8 \%$ and reduced the indoor humidty by $6 \% \mathrm{RH}$. The Mfr. B units in CC3 and the Lake House show significantly different performance. Since the operating conditions for these units are similar, the compressor speed and/or cycle length are likely driving this difference. The baseline 13 SEER heat pumps installed at CC1 show significantly lower efficiencies than the published ratings. As with the HSPF ratings, this indicates that measured efficiencies below the rated SEERs are not unique to variable speed equipment.

Table 3. Cooling Season Efficiencies

\begin{tabular}{|c|c|c|c|c|c|c|c|c|}
\hline Model & $\begin{array}{l}\text { Published } \\
\text { SEER }\end{array}$ & $\begin{array}{c}\text { SEER } \\
\text { Estimated } \\
\text { From } \\
\text { Available } \\
\text { Test Data }\end{array}$ & $\begin{array}{c}\text { OAT } \\
\text { Normali- } \\
\text { zed SEER }\end{array}$ & $\begin{array}{c}\text { Diff } \\
\text { Between } \\
\text { Normali- } \\
\text { zed SEER } \\
\text { and } \\
\text { Published }\end{array}$ & $\begin{array}{l}\text { Average } \\
\text { OAT } \\
\text { while unit } \\
\text { was } \\
\text { cooling }\end{array}$ & $\begin{array}{l}\text { Average } \\
\text { Return } \\
\text { Air Temp } \\
\quad \pm 2 \sigma\end{array}$ & $\begin{array}{c}\text { Average } \\
\text { Return } \\
\text { Air } \\
\text { Humidity } \\
\pm 2 \sigma\end{array}$ & Date Range \\
\hline & (Btu/Wh) & (Btu/Wh) & (Btu/Wh) & & ${ }^{\circ} \mathrm{F}$ & ${ }^{\circ} \mathrm{F}$ & $\% \mathrm{RH}$ & \\
\hline CC1 HP1 & 13.0 & $7.2 \pm 2.4$ & 7.1 & $-45 \%$ & 80.6 & $74.9 \pm 1.5$ & $52 \% \pm 5.1$ & $\begin{array}{l}5 / 1 / 2012 \text { to } \\
8 / 31 / 2012\end{array}$ \\
\hline $\mathrm{CC} 1 \mathrm{HP} 2$ & 13.0 & $9.3 \pm 2.4$ & 8.4 & $-35 \%$ & 78.5 & $77.2 \pm 2.1$ & $46 \% \pm 6.1$ & $\begin{array}{l}5 / 1 / 2012 \text { to } \\
8 / 31 / 2012\end{array}$ \\
\hline $\begin{array}{l}\mathrm{CC} 2 \\
\text { (Ducted } \\
\text { Inverter } \\
\text { A) } \\
\text { Overall }\end{array}$ & & $18.0 \pm 4.2$ & 17.5 & N/A & 80.5 & $75.9 \pm 1.6$ & $50 \% \pm 7.7$ & $\begin{array}{l}5 / 1 / 2012 \text { to } \\
8 / 31 / 2012\end{array}$ \\
\hline $\begin{array}{l}\text { CC2 } \\
\text { Without } \\
\text { RH } \\
\text { Control }\end{array}$ & 20.50 & $20.2 \pm 4.7$ & 18.7 & $-9 \%$ & 78.5 & $75.8 \pm 1.9$ & $54 \% \pm 3.8$ & $\begin{array}{l}5 / 1 / 2012 \text { to } \\
6 / 8 / 2012\end{array}$ \\
\hline $\begin{array}{l}\text { CC2 With } \\
\text { RH } \\
\text { Control }\end{array}$ & & $17.2 \pm 4.0$ & 17.2 & N/A & 81.3 & $76.0 \pm 1.5$ & $48 \% \pm 4.9$ & $\begin{array}{l}6 / 8 / 2012 \text { to } \\
8 / 31 / 2012\end{array}$ \\
\hline $\begin{array}{l}\text { Green } \\
\text { (Ducted } \\
\text { Inverter } \\
\text { A) }\end{array}$ & 20.50 & 17.3 & 16.8 & $-18 \%$ & 79.3 & $73.6 \pm 7.1$ & $51 \% \pm 7.7$ & $\begin{array}{l}5 / 1 / 2012 \text { to } \\
8 / 31 / 2012\end{array}$ \\
\hline $\begin{array}{l}\text { CC3 } \\
\text { (Ducted } \\
\text { Inverter } \\
\text { B) }\end{array}$ & 18.00 & $12.0 \pm 2.6$ & 11.4 & $-37 \%$ & 80.0 & $73.9 \pm 2.1$ & $47 \% \pm 6.9$ & $\begin{array}{l}4 / 1 / 2012 \text { to } \\
8 / 31 / 2012\end{array}$ \\
\hline $\begin{array}{l}\text { Lake } \\
\text { (Ducted } \\
\text { Inverter } \\
\text { B) }\end{array}$ & 18.00 & 16.2 & 15.3 & $-15 \%$ & 80.0 & $74.2 \pm 4.0$ & $57 \% \pm 10.5$ & $\begin{array}{c}4 / 8 / 2012 \text { to } \\
10 / 9 / 2012\end{array}$ \\
\hline
\end{tabular}




\subsubsection{Ducted Inverter B Cooling Operation}

As noted in the energy use analysis section, the ducted inverter B system required manual adjustments to the upstairs and downstairs dampers in order to maintain similar temperatures on both floors. In late June the downstairs damper was closed almost entirely in order to force more air to the upstairs, which was not being fully cooled due to the thermostat being located downstairs. This damper change increased the external static pressure enough to significantly reduce the airflow delivered by the BPM motor. Due to this fact, it is likely that the compressor ran at lower speeds and therefore capacities. Figure 20 and Figure 21 show the cooling energy efficiency ratio (EER) plotted along with the percent rated capacity and OAT for both cases. With the downstairs damper open, the unit ran mostly between $70 \%$ and $90 \%$ of rated capacity, but with the damper closed the unit ran mostly in the 50\% to $70 \%$ range. The roughly $20 \%$ reduction in operating capacity is attributed to the reduced airflow and resulting reduced compressor speed. In both cases the unit showed very little variation in operating capacity across the entire range of OATs with over $90 \%$ of the unit operation falling within a $20 \%$ band for both cases. As with the heating season, the cooling efficiency is largely dependent on the OAT with the efficiency decreasing as OAT increases. The narrower operating range of the ducted inverter B system at CC3 during the cooling season makes it difficult to determine if the trend of higher efficiency at higher capacities holds true for cooling.

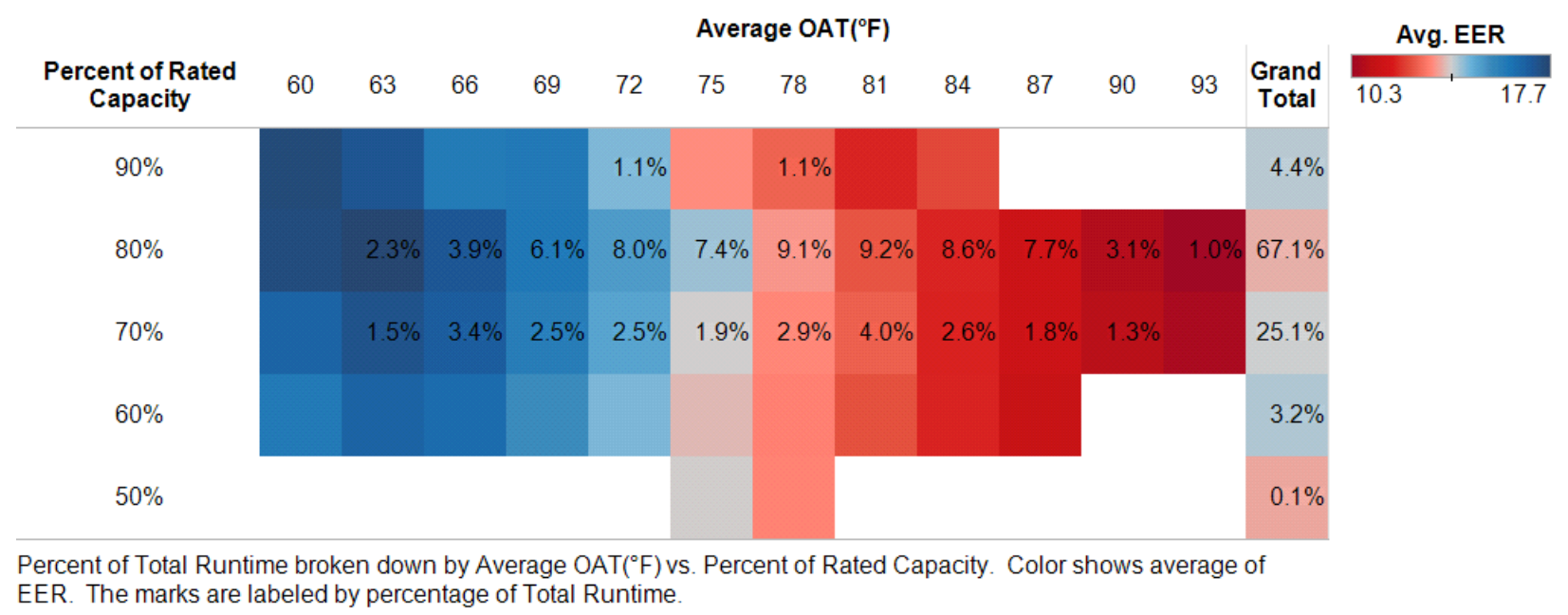

Figure 20. CC3 pre-damper adjustment performance map

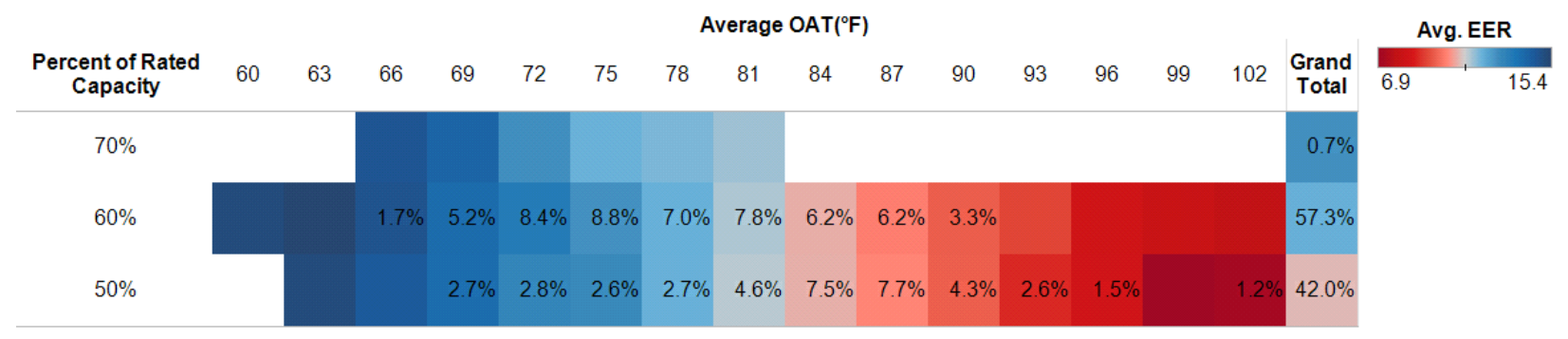

Percent of Total Runtime broken down by Average OAT $\left({ }^{\circ} \mathrm{F}\right)$ vs. Percent of Rated Capacity. Color shows average of EER. The marks are labeled by percentage of Total Runtime.

Figure 21. CC3 post-damper adjustment performance map 
The ducted inverter B system at the Lake House shows a much wider range of operating capacities when compared to the system at CC3, Figure 22. We also see that the Lake unit ran at lower capacities when the OAT and cooling load were lower and higher capacities at higher OATs and cooling loads. The unit's rated cooling capacity is at $95^{\circ} \mathrm{F}$ OAT, so it is not unexpected that the unit did not run up to $100 \%$ capacity at temperatures higher than this. The cooling load for CC3 is broken up between the pre-damper and post-damper time periods, Figure 23. Both the total cooling load and sensible cooling loads match fairly well over the temperatures with measured data. This indicates that the SHR of the unit is similar for the pre- and post-damper time periods and further supports the hypothesis that the compressor was running at lower speeds after the airflow was reduced by closing the damper.

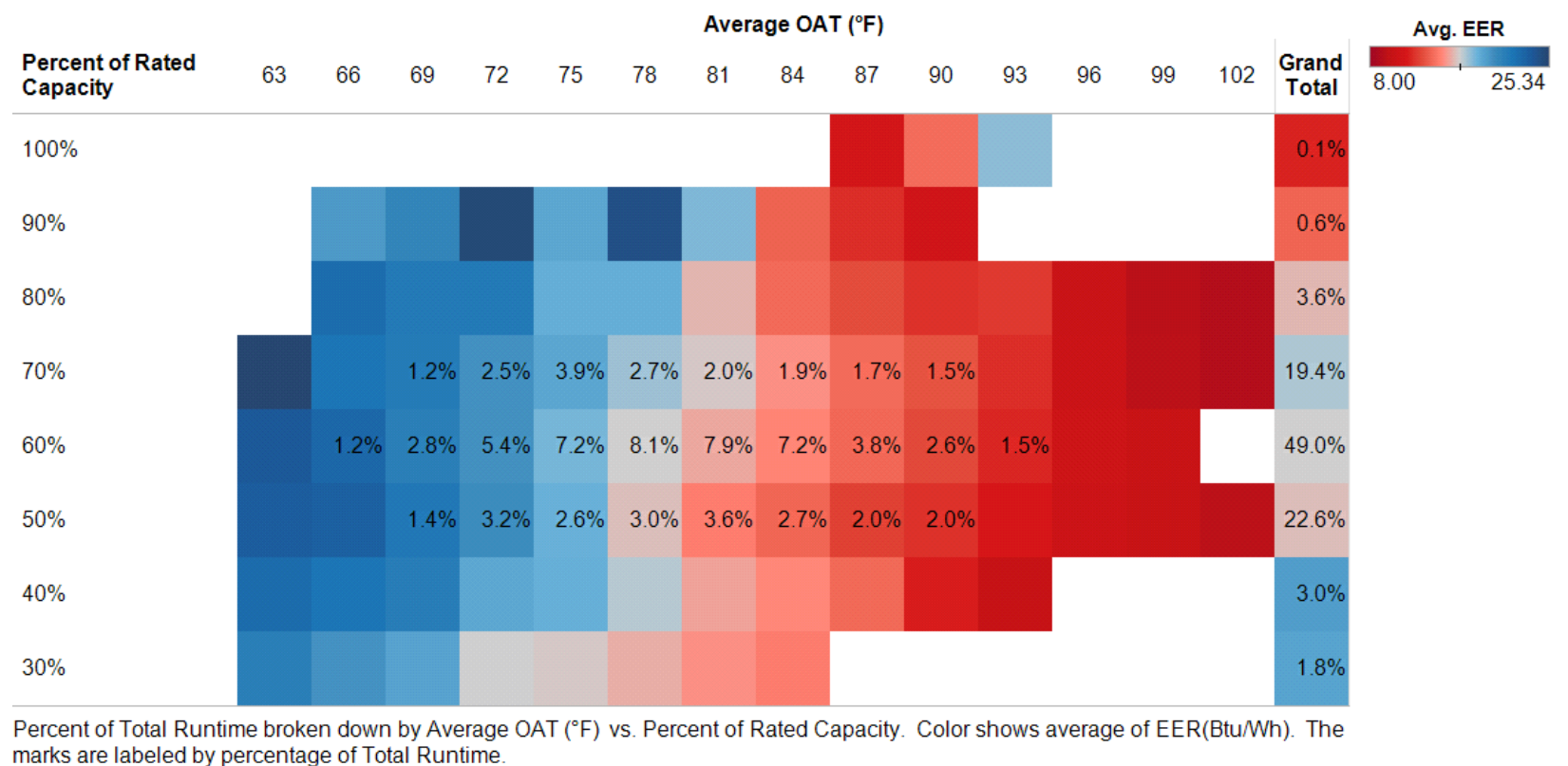

Figure 22. Lake cooling performance map 


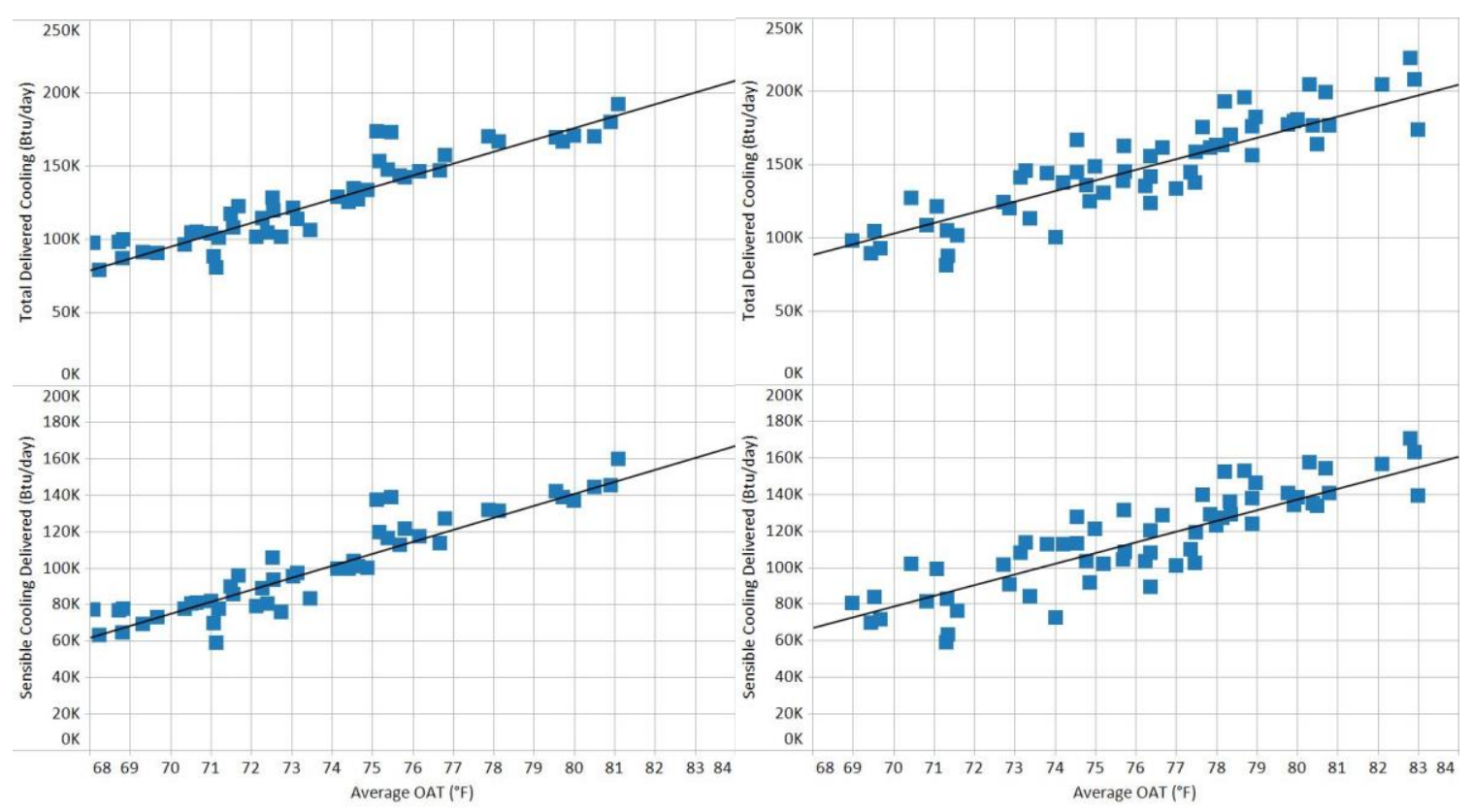

Figure 23. CC3 cooling load pre- and post-damper adjustment

Unlike in the heating season, the Lake House has a very similar cooling load to CC3 if not slightly lower, Figure 24. The operation of the units is significantly different though, which supports that there could be a component issue causing the difference in capacity and cycling of the unit.

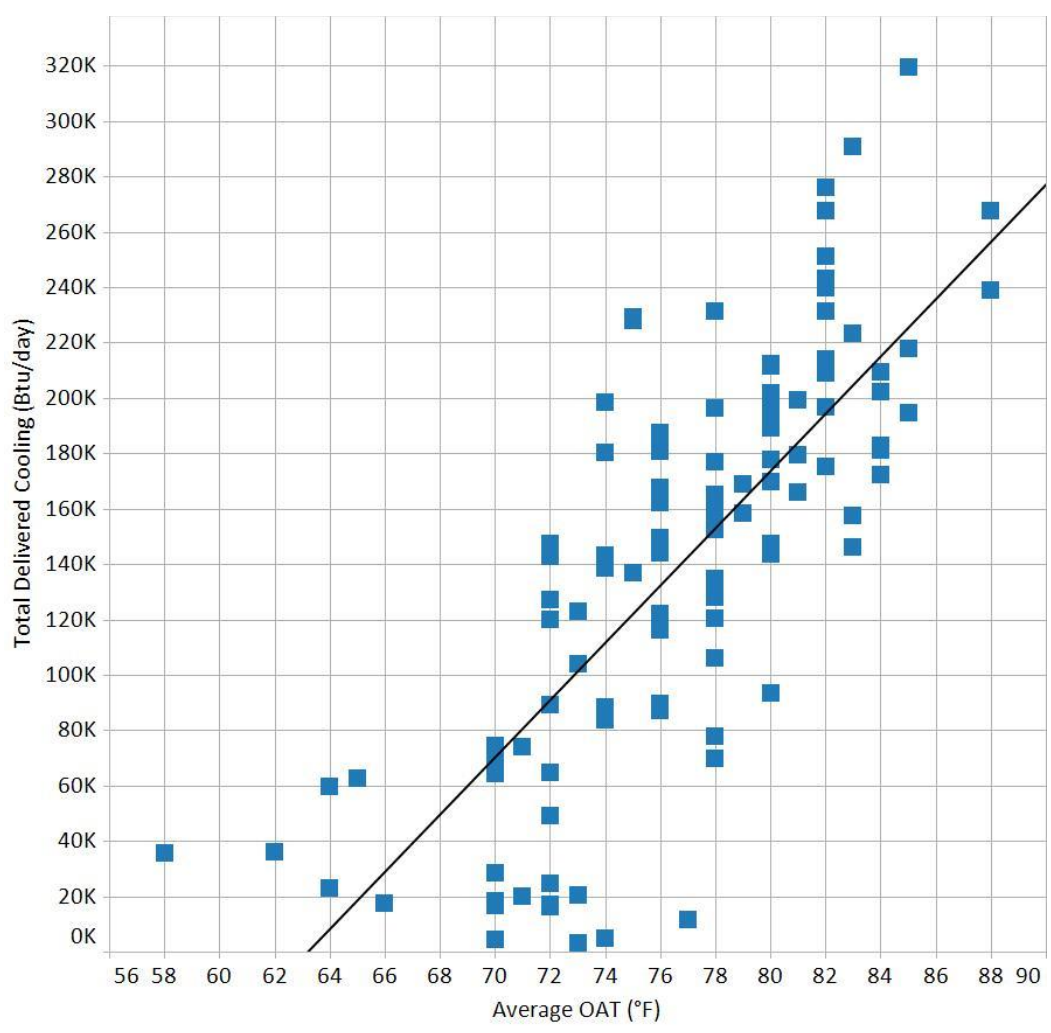

Figure 24. Lake cooling load 


\subsubsection{Ducted Inverter A Cooling Operation}

The ducted inverter A system cooling data has consistent trends with its heating data as seen in Figure 25. It runs at lower capacities during periods of milder OATs and as the OAT increases the output capacity increases as well. Looking at the trends within a fixed temperature column, the unit is more efficient at lower capacities, which is consistent with the heating season data. As with the heating season, the cooling data is very neat with very few points that appear to be out of line.

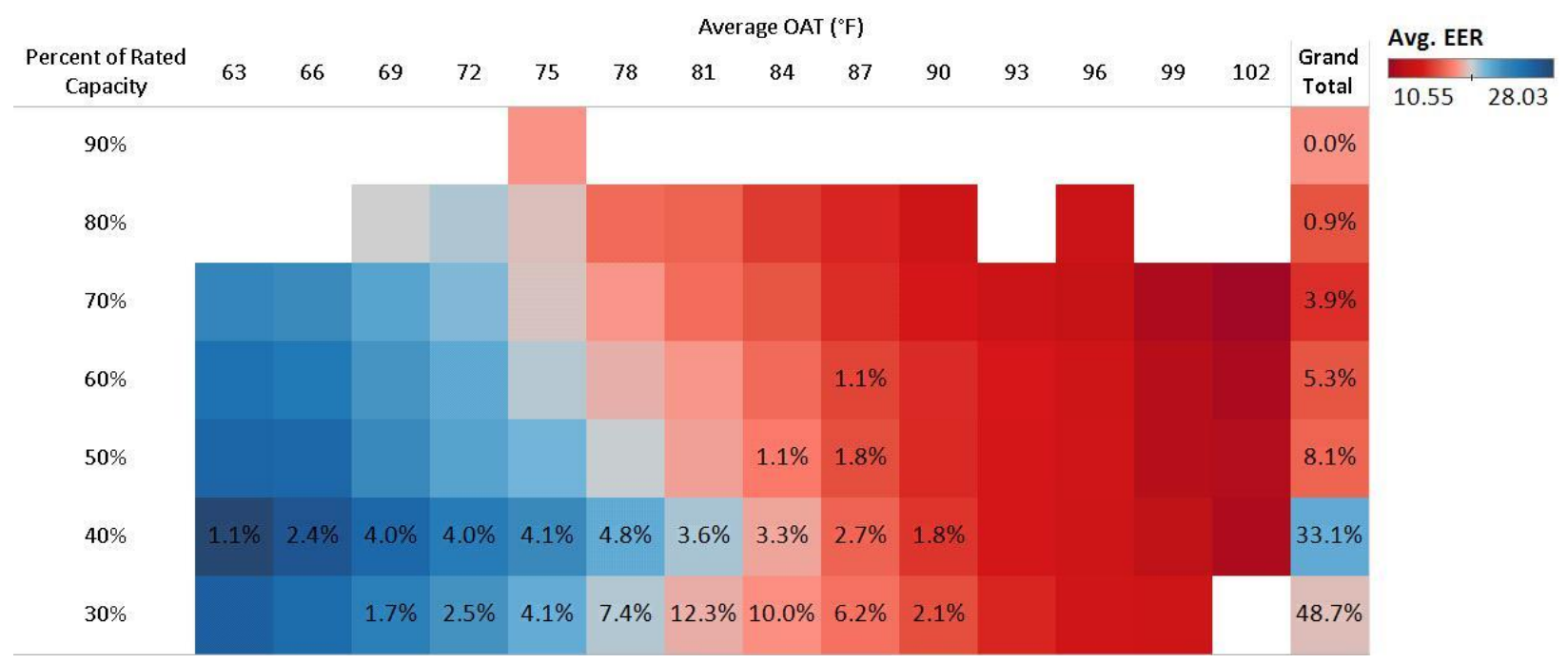

Figure 25. CC2 cooling performance map

As with the CC2 unit, the ducted inverter A system at the Green House ran the majority of the time at low capacity. However, the data is not quite as clean as the CC2 data since the house was occupied. The data shows a number of points that are over $100 \%$ of rated capacity. All of these values occur below the cooling capacity rating condition of $95^{\circ} \mathrm{F}$ OAT though, so this is not inconsistent with the rated data. The occupant of this home made frequent and large changes to the thermostat cooling set point, which is why we see such high cooling capacities at relatively cool outdoor air temperatures. The further the temperature at the thermostat is from the set point temperature, the higher the capacity the unit will run at in order to meet the set point more quickly. 


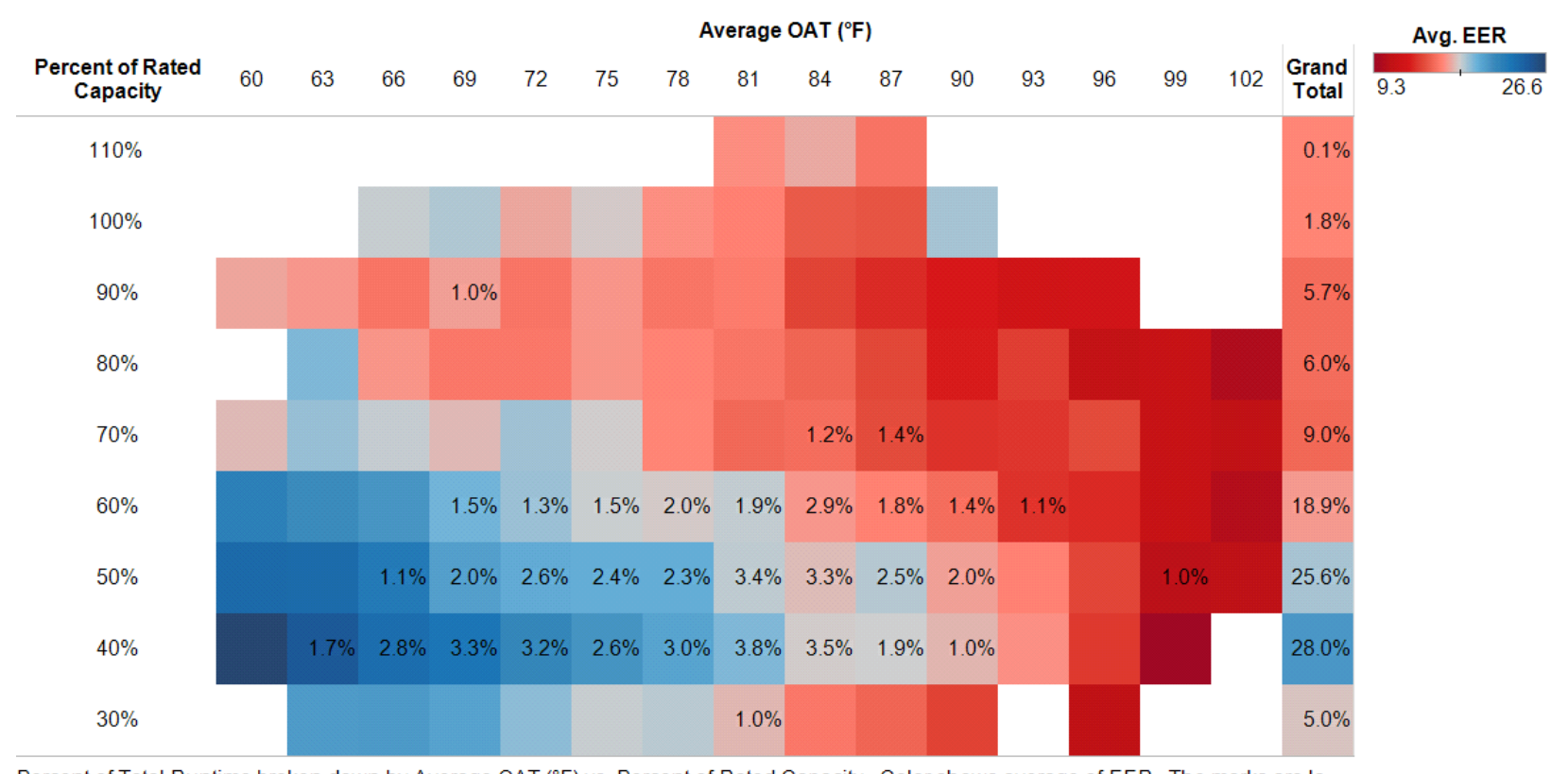

Percent of Total Runtime broken down by Average OAT $\left({ }^{\circ} \mathrm{F}\right)$ vs. Percent of Rated Capacity. Color shows average of EER. The marks are labeled by $\%$ of Total Runtime.

Figure 26. Green cooling performance map

\subsection{CASE STUDY: CYCLE LENGTH}

As noted in the prior section, the cooling performance of both baseline units was well below the published SEERs. Since these units have a single speed compressor, the efficiencies were plotted against OAT and cycle length. This allows the impact of cycle length on cooling efficiency to be viewed independent of the OAT. It also shows how cycle length varies with the change in OAT. Figure 27 shows this data for HP1, the unit that is cooling the lower level of CC1. Looking at the Grand Total column shows that $49.1 \%$ of the runtime is during cycles that are less than 10 minutes in length and $88.6 \%$ of the runtime is during cycles less than 15 minutes. While there is only limited data within constant temperature columns, it is still easy to see that the unit is more efficient when it runs longer cycles. The short cycles of this unit are likely contributing to the low measured performance. 


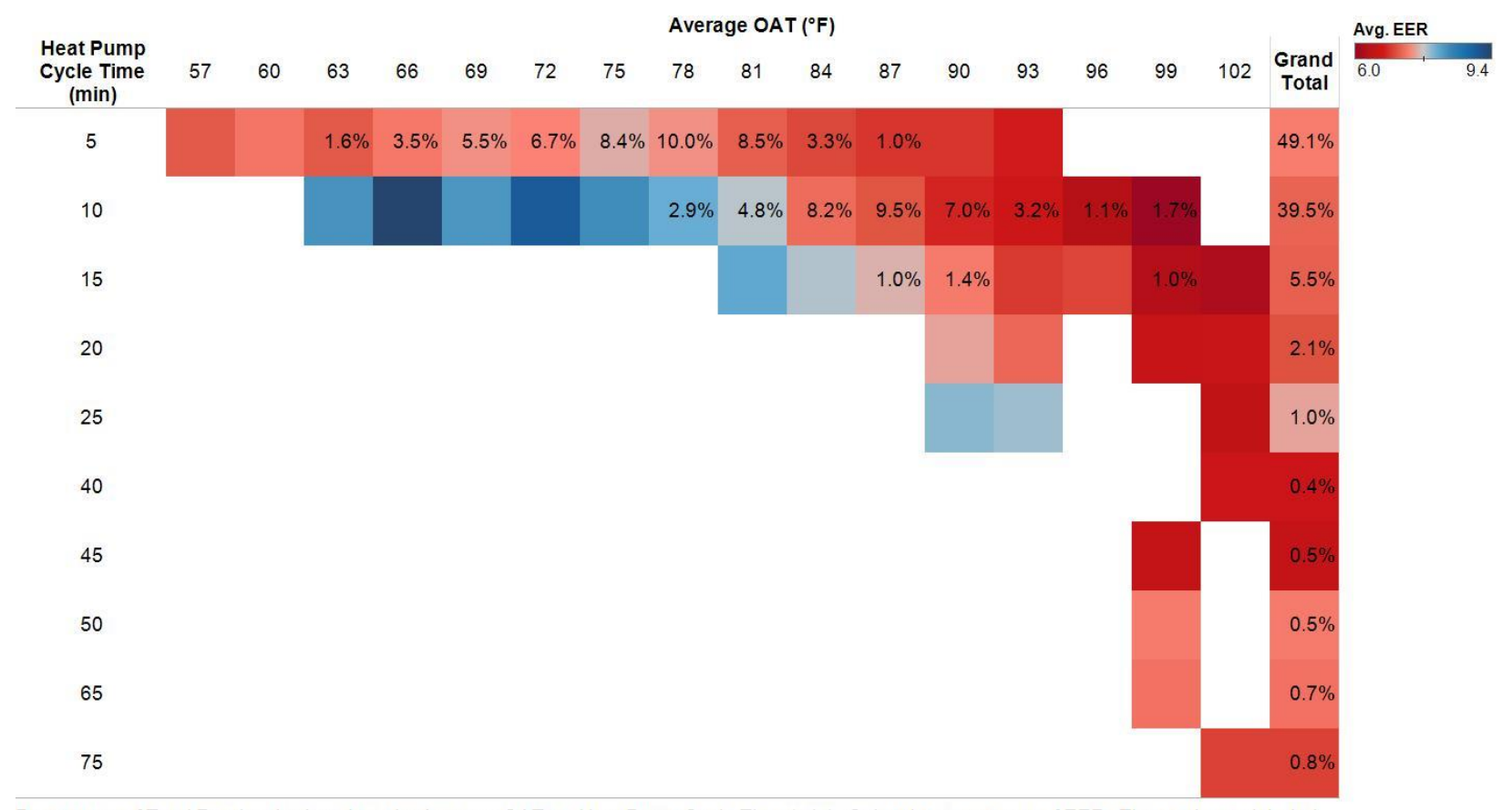

Percentage of Total Runtime broken down by Average OAT vs. Heat Pump Cycle Time (min). Color shows average of EER. The marks are labeled by Percentage of Total Runtime.

Figure 27. HP1 cooling performance map with cycle length

Data for the upstairs heat pump is plotted similarly in Figure 28. This unit generally has longer cycles with only $37.2 \%$ of the runtime occurring during cycles that are 15 minutes or less. The performance increase due to longer cycles can be seen in the measured performance, however it is likely understating the impact due to lower than ideal airflow. The measured airflow on the upstairs unit was $320 \mathrm{cfm} / \mathrm{ton}$, which is lower than the rated $420 \mathrm{cfm} /$ ton and likely reduced the cooling efficiency by about $9 \%$ based on the manufacturer's published data. This heat pump is likely sized very close to the limit due to the very long cycles, over six hours that were seen when the outdoor air temperature was highest. 


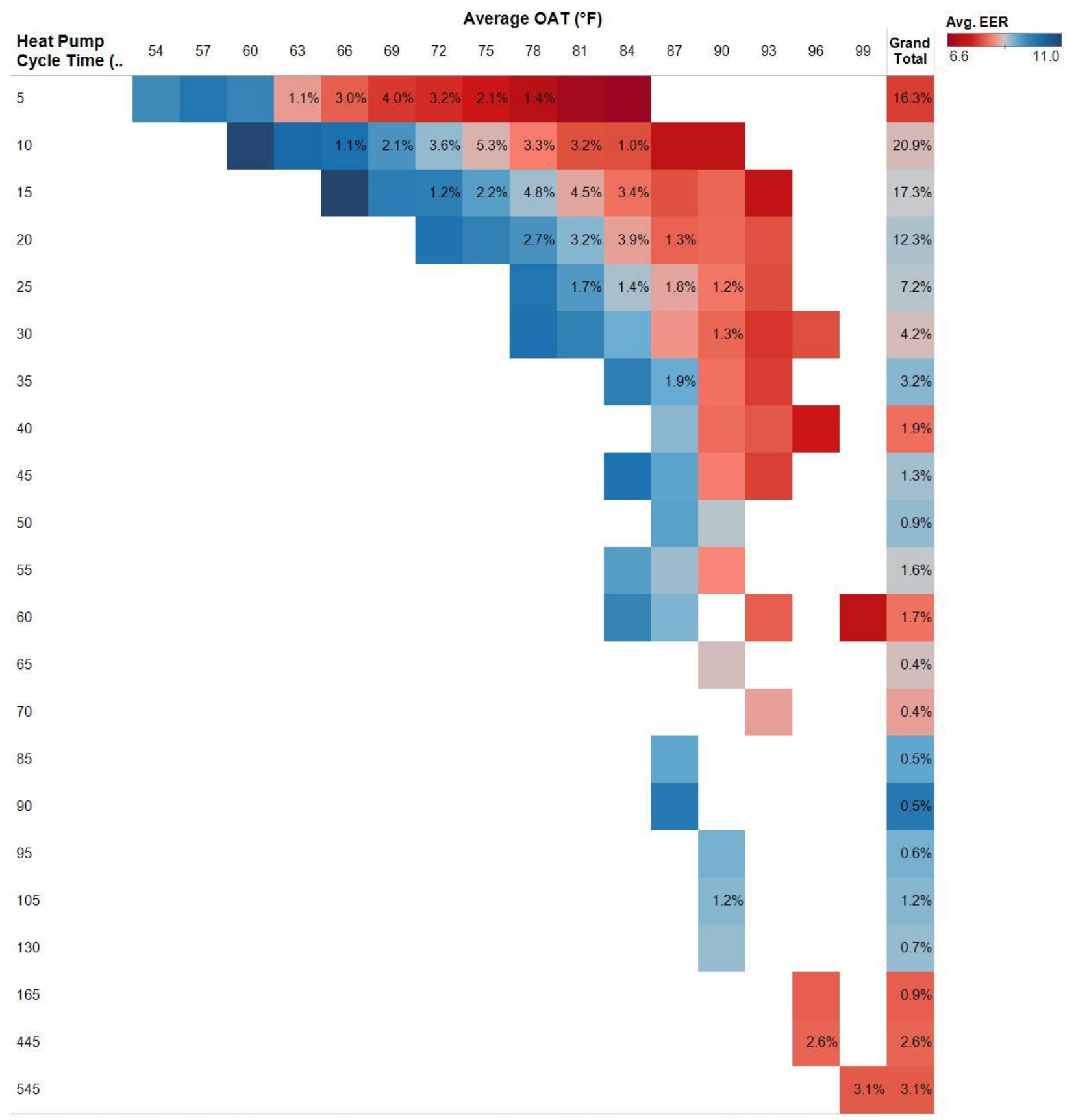

Percentage of Total Runtime broken down by Average OAT vs. Heat Pump Cycle Time (min). Color shows average of EER. The marks are labeled by Percentage of Total Runtime.

Figure 28. HP2 cooling performance color map with cycle length

For comparison, the data from the ducted inverter A system at $\mathrm{CC} 2$ has been plotted in the same fashion in Figure 29. Only 3.3\% of its runtime occurred during cycles that were 15 minutes or less, and the majority of the cycles fell in the 25-60 minute range. The longest cycle at 155 minutes was substantially less than that of the upstairs unit at $\mathrm{CC} 1$ indicating that the $\mathrm{CC} 2$ unit was more oversized than the upstairs unit at $\mathrm{CC} 1$. 


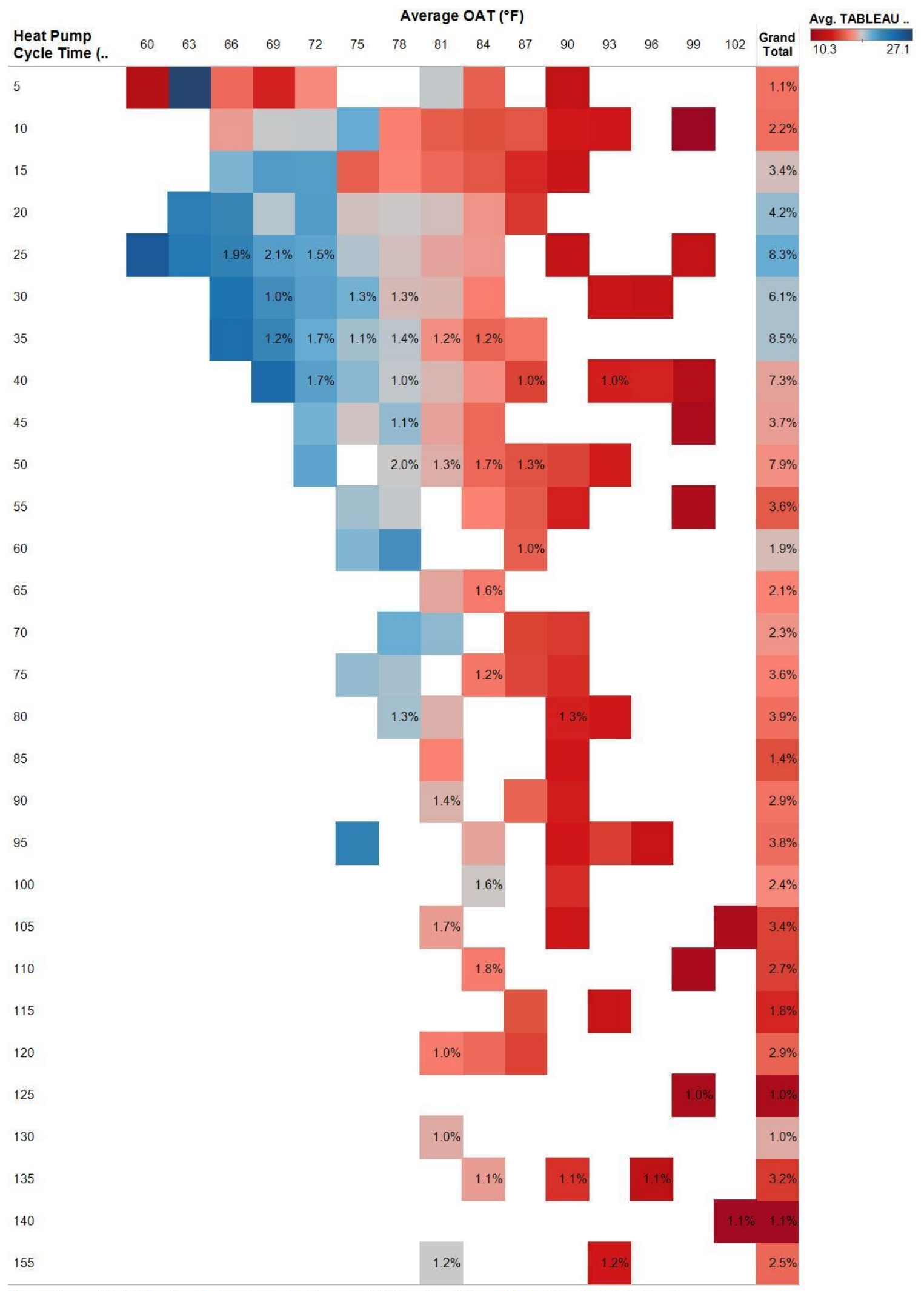

Percentage of Total Runtime broken down by Average OAT vs. Heat Pump Cycle Time ( $\mathrm{min}$ ). Color shows average of EER. The marks are labeled by Percentage of Total Runtime.

Figure 29. CC2 cooling performance color map with cycle length 


\section{CONCLUSIONS}

This report summarizes the 2012 heating and cooling season performance of variable capacity heat pumps from two different manufactures that were installed in two research homes and two instrumented, occupied homes. The houses represent a wide range of structures that ranges from the high efficiency CC3 house, to the 100+ year old Green House. The data represents testing under two different sets of weather data (Knoxville and Duluth) as well as including effects from various set points and system operating modes.

The energy use analysis indicates that the ducted inverter A system at CC2 is performing significantly better than the prior single-stage heat pump. The predicted energy savings exceed what the rated SEER and HSPF values would indicate. For the time period analyzed, the system only used resistance heat during defrost cycles, which saves energy and reduces peak power draws in the winter.

The ducted inverter B system at CC3 appears to be performing better than the prior two-stage heat pump in the heating mode, but not in the cooling mode. The original system used excessive resistance heat due to thermostat setup issue, but after applying generous corrections to eliminate this issue, the ducted inverter system still would have used less energy. However, the cooling performance of the ducted inverter system was worse than the prior heat pump with the ducted inverter system using $23 \%$ more energy than the baseline system despite the SEER values predicting a 11\% savings. This indicates that the ducted inverter system was likely operating at a cooling efficiency well below its SEER rating. The two-stage HP also had enough capacity to run in low stage for the majority of the summer, which likely improved its performance.

There is a stark difference between the operation of the ducted inverter B system at CC3 and the Lake House that is not intuitively attributable to differences in the house loads. The CC3 unit ran at higher capacities despite having lower heating loads and similar cooling loads to satisfy. This leads us to believe that the unit has an issue that is affecting the compressor speed control. The manufacturer has indicated that the unit runs at higher speeds during startup. Once the unit has stabilized it will modulate its speed as appropriate. This could be the reason for the difference in operation if the CC3 unit meets the temperature set point during the stabilization period. However, this period seems long on the unit at CC3, since it is not unusual to have cycles exceeding 30 minutes.

The research houses with simulated occupancy provided data that was much easier to extract meaningful operational trends from. The behavior of occupants is often inconsistent and has a large enough impact on the heating and cooling energy use that it can mask trends in the data.

While all of the variable capacity heat pumps performed at efficiencies lower than their AHRI ratings, the same was true of the single-stage baseline heat pumps. The Mfr. A system at CC2 provided the highest heating and cooling efficiencies of all of the units tested, however its heating efficiency was well below its rated HSPF. While its savings when compared to the original 9.75 HSPF system installed at CC2 exceeded AHRI rating predictions, its measured efficiency compared to the 7.7 HSPF rated heat pumps at $\mathrm{CC} 1$ did not show the same percentage of savings as the AHRI ratings would indicate. Using the baseline 
heat pumps as a reference, all of the other variable speed heat pumps would have provided energy savings that were consistent or exceeding those indicated by the rated SEERs and HSPFs.

With the exception of the ducted inverter B system at CC3, the variable speed heat pumps ran at lower capacities and for longer cycle durations than the baseline heat pumps. Based on the CC1 house, which is a common floor plan and construction technique for many new homes in the area, part load performance degradation has a significant impact on units that are oversized for their load. Due to imbalances in the heating and cooling loads and the limited capacity range of ducted, split system heat pumps, it is difficult in most climates to have a heat pump that is properly sized for both heating and cooling. Variable capacity heat pumps offer a solution to this by allowing the unit to run at reduced capacity for longer periods of time thereby reducing cycling losses seen with single speed heat pumps. They also typically have higher heating capacities at lower temperatures than standard heat pumps, which reduces their dependence on strip heat for supplemental heating capacity.

\section{FUTURE WORK}

The detailed heating and cooling load data being collected for the three research houses in the Campbell Creek subdivision will be extremely valuable in fine tuning the Energy Plus house models that are currently being developed. Once the house models accurately match the measured loads, the HVAC energy use data can be compared against the Energy Plus equipment models. This will provide insight as to how well the Energy Plus equipment models represent actual equipment, which is of particular interest for the new inverter-driven, variable speed heat pumps. It is of critical importance that energy modeling software accurately captures the energy savings between standard heat pump and variable speed heat pumps if this technology is to see more widespread acceptance.

The two single speed heat pumps in the $\mathrm{CC} 1$ research house were recently retrofitted with two variable capacity heat pumps with inverter driven compressors. This will allow a direct comparison between minimum efficiency heat pumps and variable capacity heat pumps in a typical recently built home.

\section{REFERENCES}

Christian, J.E., A.C. Gehl, P.R. Boudreaux, J.R. New. 2010. Campbell Creek TVA 2010 First Year Performance Report July 1, 2009 August 31, 2010, ORNL/TM-2010/206. Oak Ridge, TN: Oak Ridge National Laboratory. http://info.ornl.gov/sites/publications/files/Pub26374.pdf.

Boudreaux, P.R., K. Biswas, R. K. Jackson. 2012. Advancing Residential Retrofits in the Mixed-humid Climate to Achieve Deep Energy Savings: Final Report on Knoxville, TN Homes, ORNL/TM-2012/533. Oak Ridge, TN: Oak Ridge National Laboratory. http://info.ornl.gov/sites/publications/Files/Pub39986.pdf. 
Jackson, R. K., E. Kim, S. Roberts, R. Stephenson. 2012. Advancing Residential Retrofits in Atlanta, ORNL/TM-2012/488. Oak Ridge, TN: Oak Ridge National Laboratory.

http://info.ornl.gov/sites/publications/Files/Pub33538.pdf

Munk, J.D. 2012. Performance of Variable Capacity Heat Pumps in a Mixed Humid Climate. ORNL/TM2012/17. Oak Ridge, TN: Oak Ridge National Laboratory. http://info.ornl.gov/sites/publications/Files/Pub34446.pdf. 



\section{APPENDIX}

\section{Calculations}

From the adjusted air side measurements described in the previous section, system cooling capacity is given by:

$$
\operatorname{Cap}_{c}=\dot{Q} \rho C_{p}\left(T_{\text {ret }}-T_{\text {sup }}\right)+\dot{Q} \rho\left(\omega_{\text {sup }}-\omega_{\text {ret }}\right)\left(h g_{\text {ret }}-h f_{\text {sup }}\right)
$$

Where $\rho$ is the air density calculated at the return temperature from ideal gas assumptions, $\mathrm{C}_{\mathrm{p}}$ is the constant pressure specific heat, and $\omega$ is the humidity ratio of the air mixture calculated from the temperature and RH measurements at the supply and return. The terms $\mathrm{hg}_{\text {ret }}$ and $\mathrm{hf}_{\text {sup }}$ are the specific enthalpies of the saturated gaseous and liquid water calculated at the supply and return air temperatures respectively.

The heating capacity is calculated in a similar fashion as:

$$
\operatorname{Cap}_{h}=\dot{Q} \rho C_{p}\left(T_{\text {sup }}-T_{\text {ret }}\right)
$$

The efficiency of the unit in either mode can then be expressed as:

$$
C O P=\frac{\text { Cap }}{E_{\text {ln }}+E_{\text {out }}}
$$

Where capacity and power are expressed in the same units.

The efficiencies of the units were normalized by using the same weights as used in the AHRI 210/240 standard for HSPF and SEER calculations. The first step to this process was calculating an average HPF or EER for each temperature bin used in the HSPF or SEER ratings. This was done by summing the total delivered heating or cooling in each temperature bin, $\mathrm{j}$, and dividing it by the total energy use for each temperature bin. The HSPF calculation is as follows:

$$
H S P F=\frac{\sum_{j}^{J} n_{j} \text { Capacity }_{j}}{\sum_{j}^{J} \text { Energy }_{j}}
$$

The average HPF and EER at each temperature bin are converted to an energy input ratio (EIR) using as follows:

$$
E I R_{j}=\frac{1}{H P F_{j}}
$$


The HSPF is then calculated as follows:

$$
H S P F=\left(\frac{\sum_{j}^{J} B L(j) n_{j} E I R_{j}}{\sum_{j}^{J} B L(j) n_{j}}\right)^{-1}
$$

Where $n_{j}$ is equal to the hour of unit operation in temperature bin $j$ and $B L(j)$ is the capacity required from the unit to satisfy the building load at temperature bin $\mathrm{j}$.

\section{SEER and HSPF Normalization}

Table A-1 shows the average cooling data for each unit for the Region IV SEER temperature bins. The weighting of the efficiency in each temperature bin that goes into the overall SEER calculation is also provided. Table A-2 shows the same information for the Region IV HSPF calculation and normalization. For temperatures where sufficient data was not available linear interpolation was used to fill in the missing data, shown in italics. Linear extrapolation was used for the very low temperature HSPF data with a minimum value of $3.4 \mathrm{Btu} / \mathrm{Wh}$ being used to indicate $100 \%$ resistance heat use. 
Table A-1. SEER Normalization

\begin{tabular}{|c|c|c|c|c|c|c|c|c|c|}
\hline OAT Bin & $\begin{array}{l}\text { Weighting } \\
\text { in SEER } \\
\text { Calc }\end{array}$ & CC1 HP1 & CC1 HP2 & $\begin{array}{c}\text { CC2 } \\
\text { Overall } \\
\text { (Ducted } \\
\text { Inverter A) }\end{array}$ & $\begin{array}{l}\text { CC2 no } \\
\text { RH control } \\
\text { (Ducted } \\
\text { Inverter } \\
\text { A) }\end{array}$ & $\begin{array}{l}\text { CC2 with } \\
\text { RH control } \\
\text { (Ducted } \\
\text { Inverter } \\
\text { A) }\end{array}$ & $\begin{array}{c}\text { CC3 } \\
\text { (Ducted } \\
\text { Inverter B) }\end{array}$ & 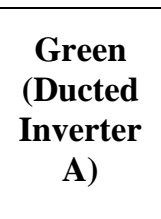 & $\begin{array}{c}\text { Lake } \\
\text { (Ducted } \\
\text { Inverter B) }\end{array}$ \\
\hline$\left({ }^{\circ} \mathrm{F}\right)$ & $(\%)$ & (Btu/Wh) & $(\mathrm{Btu} / \mathrm{Wh})$ & (Btu/Wh) & (Btu/Wh) & $(\mathrm{Btu} / \mathrm{Wh})$ & (Btu/Wh) & (Btu/Wh) & $(\mathrm{Btu} / \mathrm{Wh})$ \\
\hline 67 & 3.6 & 7.5 & 8.4 & 23.4 & 25.0 & 22.4 & 15.2 & 20.7 & 21.9 \\
\hline 72 & 13.7 & 7.3 & 8.1 & 21.6 & 23.6 & 20.8 & 13.7 & 19.2 & 20.1 \\
\hline 77 & 22.0 & 7.4 & 8.3 & 19.9 & 21.1 & 19.4 & 12.7 & 18.5 & 17.8 \\
\hline 82 & 23.2 & 7.2 & 8.6 & 18.0 & 18.7 & 17.7 & 11.7 & 17.3 & 15.5 \\
\hline 87 & 19.4 & 7.1 & 8.7 & 16.2 & 16.9 & 15.9 & 10.7 & 15.8 & 13.9 \\
\hline 92 & 11.9 & 6.7 & 8.5 & 14.3 & 16.2 & 14.1 & 9.7 & 14.5 & 12.5 \\
\hline 97 & 4.9 & 6.5 & 8.1 & 12.8 & 13.6 & 12.8 & 8.1 & 13.0 & 10.5 \\
\hline 102 & 1.3 & 6.1 & 7.3 & 11.2 & 11.8 & 11.2 & 6.9 & 10.7 & 9.5 \\
\hline $\begin{array}{l}\text { Region IV } \\
\text { Normalized } \\
\text { SEER }\end{array}$ & & 7.1 & 8.4 & 17.5 & 18.7 & 17.2 & 11.4 & 16.8 & 15.3 \\
\hline
\end{tabular}


Table A-2. HSPF Normalization

\begin{tabular}{|c|c|c|c|c|c|c|}
\hline OAT Bin & $\begin{array}{c}\text { Weighting } \\
\text { in HSPF } \\
\text { Calc }\end{array}$ & CC1 HP1 & CC1 HP2 & $\begin{array}{c}\text { CC2 } \\
\text { (Ducted } \\
\text { Inverter A) }\end{array}$ & $\begin{array}{c}\text { CC3 } \\
\text { (Ducted } \\
\text { Inverter B) }\end{array}$ & $\begin{array}{c}\text { Lake } \\
\text { (Ducted } \\
\text { Inverter B) }\end{array}$ \\
\hline$\left({ }^{\circ} \mathrm{F}\right)$ & $(\%)$ & (Btu/Wh) & $(\mathrm{Btu} / \mathrm{Wh})$ & (Btu/Wh) & (Btu/Wh) & $(\mathrm{Btu} / \mathrm{Wh})$ \\
\hline-8 & 0.3 & 3.4 & 3.4 & 3.4 & 5.8 & 5.8 \\
\hline-3 & 0.6 & 3.4 & 3.4 & 3.4 & 6.0 & 6.0 \\
\hline 2 & 1.6 & 3.4 & 3.4 & 4.1 & 6.3 & 62 \\
\hline 7 & 3.2 & 3.4 & 3.5 & 4.8 & 6.5 & 6.5 \\
\hline 12 & 5.8 & 3.2 & 4.6 & 5.5 & 6.7 & 6.7 \\
\hline 17 & 7.2 & 3.5 & 4.4 & 6.6 & 7.3 & 7.0 \\
\hline 22 & 9.9 & 3.7 & 5.4 & 7.3 & 7.4 & 7.4 \\
\hline 27 & 13.8 & 4.6 & 5.8 & 7.7 & 7.5 & 7.5 \\
\hline 32 & 17.4 & 6.2 & 6.3 & 8.0 & 7.4 & 7.8 \\
\hline 37 & 12.8 & 7.1 & 6.8 & 10.9 & 8.3 & 8.0 \\
\hline 42 & 9.6 & 7.8 & 7.5 & 12 & 9.0 & 7.7 \\
\hline 47 & 7.0 & 8.2 & 8.2 & 12.7 & 9.3 & 7.8 \\
\hline 52 & 5.6 & 7.8 & 8.9 & 12.9 & 10.1 & 7.9 \\
\hline 57 & 3.7 & 7.7 & 9.4 & 13.9 & 11.5 & 8.1 \\
\hline 62 & 1.7 & 7.7 & 9.9 & 14.0 & 12.9 & 8.3 \\
\hline $\begin{array}{c}\text { Region IV } \\
\text { Normalized } \\
\text { HSPF }\end{array}$ & & 5.2 & 6.0 & 8.3 & 7.9 & 7.5 \\
\hline
\end{tabular}

\section{Measurements}

Data were collected for the four variable capacity unit equipped homes (CC2, CC3, Green, and Lake) over a test period spanning the days between $2 / 1 / 2012$ and 8/31/2012, at either 15 or 30 second intervals depending on the house. Data for the single-speed, baseline house is available at 15 minute intervals for the period between 9/01/11 and 8/31/12 and is, for all intent and purpose continuous. The air-side parameters being measured which are used in this analysis are listed in Table A-3. 
Table A-3. Measurement Types and Locations

\begin{tabular}{|c|c|c|}
\hline Measurement & Symbol & Physical Location \\
\hline $\begin{array}{l}\text { Supply Air Temperature }(\mathrm{F}) \text { and } \\
\% \mathrm{RH}\end{array}$ & $\mathrm{T}_{\text {sup }}, \mathrm{RH}_{\text {sup }}$ & Supply plenum \\
\hline $\begin{array}{l}\text { Return Air Temperature }(\mathrm{F}) \text { and } \\
\% \mathrm{RH}\end{array}$ & $\mathrm{T}_{\text {ret }}, \mathrm{RH}_{\text {ret }}$ & Return plenum \\
\hline Indoor Power (W) & $\dot{\mathrm{E}}_{\text {in }}$ & At circuit breaker \\
\hline Outdoor Power (W) & $\dot{\mathrm{E}}_{\text {out }}$ & At circuit breaker \\
\hline Fan Power (W) all except Lake & $\dot{\mathrm{E}}_{\mathrm{fan}}$ & At indoor unit \\
\hline $\begin{array}{l}\text { Compressor Power }(\mathrm{W}) \text { all } \\
\text { except Lake }\end{array}$ & $\dot{\mathrm{E}}_{\text {comp }}$ & At outdoor unit \\
\hline Airflow (CFM)Mfr. A Houses & $\dot{\mathrm{Q}}$ & $\begin{array}{l}\text { From Mfr. A controller data and correlated to measured } \\
\text { airflows where available }\end{array}$ \\
\hline Airflow (CFM) Mfr. B Houses & $\dot{\mathrm{Q}}$ & $\begin{array}{l}\text { From fan power and Mfr. B specs and correlated to measured } \\
\text { airflows where available. }\end{array}$ \\
\hline Airflow (CFM) Baseline House & $\dot{\mathrm{Q}}$ & From fan power and measured airflows. \\
\hline
\end{tabular}

In addition to air-side measurements, the two ducted inverter A systems were instrumented for refrigerant-side measurements. The refrigerant mass flow rate was calculated based on the compressor map and the compressor speed logged from the systems' control boards. The refrigerant-side results were then compared to the air-side results for both houses.

In $\mathrm{CC} 2$, the airflow was measured with a powered flow hood and this value was compared to the values being logged by the controller. A linear correlation was then made between the system's airflow value and the measured airflow values. This corrected value was used in the regression analysis in this report. The condensate removed during the air conditioning process was also collected in a tipping bucket gauge. Since the latent capacity of the unit is highly sensitive to the relative humidity (RH) measurements and the RH sensors have comparatively low accuracy and drift over time, the condensate collection was used to correct the RH measurements. This was done by filtering out the transient data by removing points for which the unit had been running for less than 30 minutes. At this point it is assumed that the coil is fully wetted and the drain pan is filled to a level that will allow continuous flow of condensate. The supply and return RH measurements were then offset in equal increments until the best match between the air-side calculated condensate flow and the actual measured condensate flow was achieved. Prior to the corrections, air-side measurements were significantly lower than those calculated from the refrigerantside measurements. After the correction factors were applied, the correlations were within $10 \%$ for the $\mathrm{CC} 2$ cooling data and $4 \%$ for the $\mathrm{CC} 2$ heating data. Similar airflow and $\% \mathrm{RH}$ adjustments were made for the $\mathrm{CC} 1$ and $\mathrm{CC} 3$ homes. 
The ducted inverter A system at the Green House did not have a tipping bucket to measure the condensate and, since it was an occupied house, did not have the airflow measured with a powered flow hood. Given the discrepancies in airflow and RH measurements which were seen at $\mathrm{CC} 2$, it was decided that the heating season refrigerant-side measurements would be used to correct the unit airflow and that the cooling season refrigerant-side measurements would then be used to correct the RH measurements. The airflow correction was made by comparing the steady state air-side data points to the corresponding refrigerant-side data points and adjusting the airflow for best fit. Even after this correction, there was still a $10 \%$ difference between the air-side and refrigerant-side results. This discrepancy is not unexpected given the limited data set which was available for the heating season.

For the Green House cooling season, the airflow correction for the heating season was applied to the data and the results were compared the refrigerant-side analysis. These values showed relatively close agreement so no adjustments to the RH measurements were necessary.

The Lake House is not instrumented with either condensate or refrigerant side measurements. Because of this, as well as the fact that the home is occupied, no adjustments were made to the air side measurements for this home.

\section{Uncertainty Calculations}

Uncertainty calculations were performed using EES software. Calculations were performed using average values for the conditions required to perform the efficiency calculation. The airflow accuracy was assumed to be $15 \%$, which accounted for the majority of the uncertainty in the calculations. A sample output is shows below in Figure A-1. 


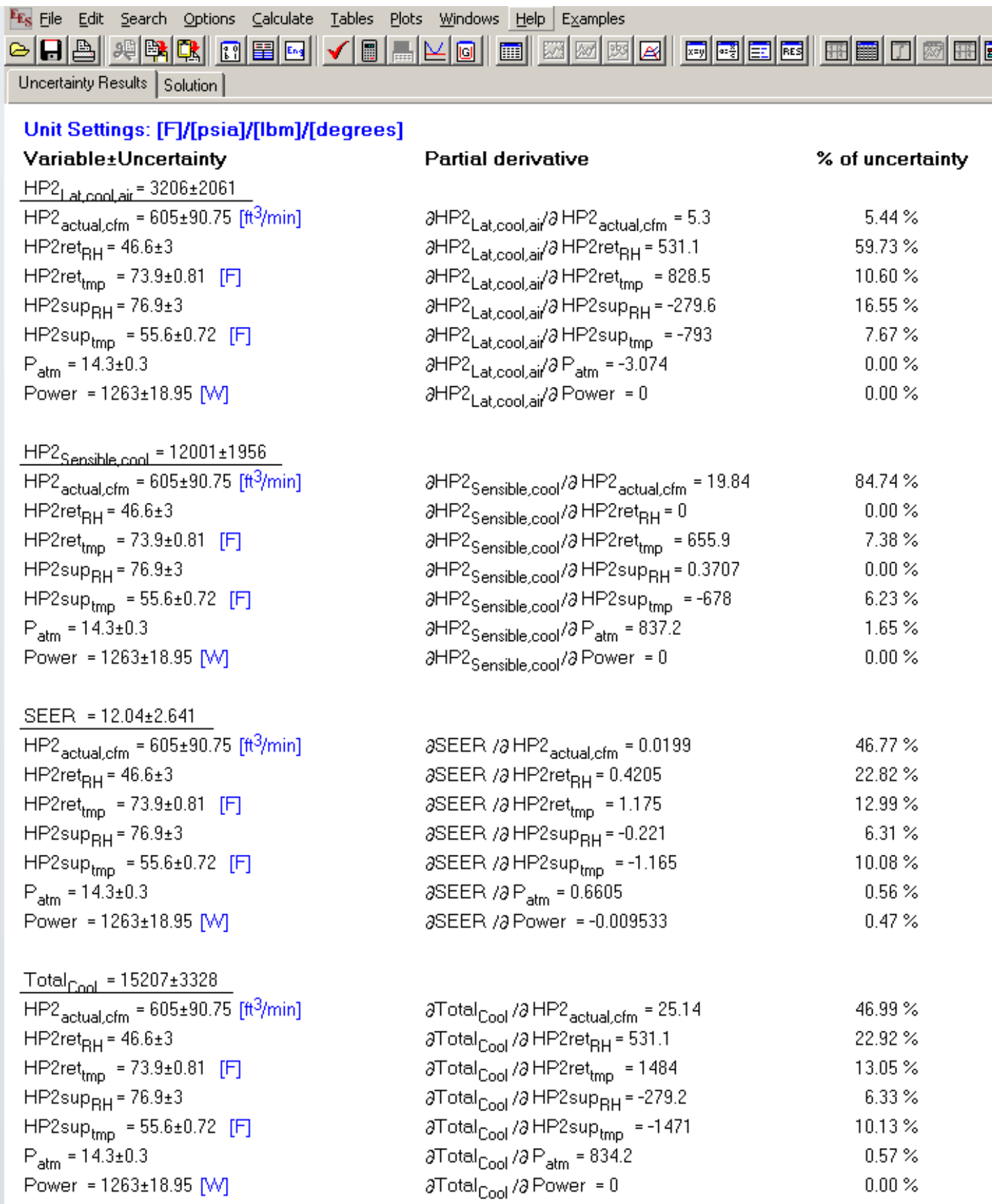

Figure A-1. Sample Uncertainty Calculation 